\title{
Review
}

\section{Carbon catabolite repression in yeast}

\author{
Juana M. GANCEDO \\ Instituto de Investigaciones Biomédicas del C.S.I.C., Facultad de Medicina UAM, Madrid, Spain
}

(Received December 23, 1991) - EJB 911721

Control of gene expression is a basic regulatory mechanism of living organisms. In microorganisms, glucose or other rapidly metabolizable carbon sources repress the expression of genes that code for enzymes related to the metabolism of other carbon sources. This phenomenon, known as catabolite repression, allows microorganisms to cope effectively with changes in the carbon sources present in their environment. In the case of Escherichia coli, a model to explain at the molecular level the mechanism of catabolite repression has been worked out (Ullmann, 1985; Saier, 1989), although some of its elements remain unidentified.

Yeasts are also subject to carbon catabolite repression but the underlying mechanism(s) is less understood than it is in $E$. coli and we do not yet know how glucose exerts its repressive effect. In the present article I will review information gathered in the last few years on a variety of catabolite-repressible systems, try to integrate it and to elaborate a scheme for carbon catabolite repression consistent with the results obtained. Although this review will be centered around Saccharomyces cerevisiae, reference to other yeast species will be made when information is available.

The degree of repression caused by glucose depends strongly on the enzyme affected and the strain used. As shown in Table 1, it can vary from about 800 -fold for invertase to less than 10-fold for aconitase, cytochrome $c$ oxidase or isocitrate dehydrogenase. In most cases, the decrease in enzyme levels caused by glucose is paralleled by a decrease in the concentration of the corresponding mRNA. This could be due to an effect of glucose either on the rate of transcription, or on the stability of the corresponding mRNA or on both.

Direct measurements of transcription rates have been performed in only a few cases. For the genes $C Y C l$, encoding iso-1 cytochrome $c$, and $M A L 6 S$, encoding maltase, it was found that derepressed cells synthesized the corresponding mRNAs 6 times and 15 times faster, respectively, than repressed cells (Zitomer et al., 1979; Federoff et al., 1983a). It should be noted that, in the case of maltase, an induction by maltose is superimposed on the process of catabolite repression, but even in the presence of maltose, the addition of glucose to a yeast culture causes an approximately 15 -fold decrease in the rate of transcription of the MAL6S gene in

Correspondence to J. M. Gancedo, Instituto de Investigaciones Biomédicas del C.S.I.C., Arturo Duperier 4, E-28029 Madrid, Spain less than $20 \mathrm{~min}$. It is noteworthy that glucose also affects the stability of the mRNAs corresponding to the genes mentioned. The half-life of the $C Y C l \mathrm{mRNA}$ in derepressed cells is about $12 \mathrm{~min}$ (Zitomer et al., 1979), while it decreases to about $2 \mathrm{~min}$ in the presence of glucose (Zitomer and Nichols, 1978). In the case of maltase, the half-life of the corresponding mRNA decreases from $25 \mathrm{~min}$ to $6 \mathrm{~min}$ upon glucose addition (Federoff et al., 1983 b). It appears therefore that, at least for certain genes, glucose affects both DNA transcription and mRNA stability. However, since there are no data on the factors which affect mRNA stability differentially, I will deal only with the effects of glucose on the rate of transcription of a variety of genes.

It can be noted that in S. cerevisiae and some other yeasts the presence of glucose can affect enzyme levels, not only through a decrease in the transcription rate but also through an increase in the degradation rate of the corresponding proteins. This last process is known as catabolite inactivation; it appears to be restricted to a limited number of enzymes and its underlying mechanism has not yet been unravelled (Gancedo and Serrano, 1989; Chiang and Schekman, 1991).

\section{THE ELEMENTS OF THE SYSTEM}

The process of repression is initiated in response to a signal which is formed when glucose or related sugars are present in the medium. The formation of this signal requires the activity of one or more proteins and the signal must be received and transduced to slow down or stop the transcription of the affected gene(s). The signal produced by glucose is not likely to interact directly with DNA but instead could act by altering the conformation of a regulatory protein, through either an allosteric or a covalent modification. As shown in Fig. 1 the regulatory protein(s), which respond to the glucose signal, could affect directly the transcription of the regulated gene or act on another regulatory gene originating a regulatory cascade. The repression mechanism would require at least three elements: the signal produced by glucose, a protein coded by a trans-acting regulatory gene, and a cis-acting element located in the promoter of the regulated gene, able to respond to the protein coded by the regulatory gene. Control by glucose could be positive or negative, that is glucose could activate a repressing protein or could inhibit an activating 
Table 1. Repression of yeast enzymes by glucose.

\begin{tabular}{|c|c|c|c|c|}
\hline \multirow[t]{2}{*}{ Enzyme } & \multicolumn{2}{|c|}{ Specific activity } & \multirow{2}{*}{$\begin{array}{l}\text { Repression } \\
\text { factor }\end{array}$} & \multirow[t]{2}{*}{ Reference } \\
\hline & - Glc & + Glc & & \\
\hline & \multicolumn{2}{|c|}{$\mathrm{mU} / \mathrm{mg}$ protein } & & \\
\hline Invertase & 130 & $<0.2$ & 750 & Estruch \& Carlson 1990a \\
\hline Alcohol dehydrogenase & 1850 & 15 & 120 & Williamson et al. 1981 \\
\hline Maltase & 180 & 2 & 90 & Entian \& Zimmermann 1982 \\
\hline Malate synthase & 82 & $<1$ & 80 & Polakis \& Bartley 1965 \\
\hline Isocitrate dehydrogenase (NADP) & 214 & 26 & 80 & Polakis \& Bartley 1965 \\
\hline Phosphoeno/pyruvate carboxykinase & 300 & $<5$ & 60 & Gancedo \& Schwerzmann 1976 \\
\hline Fructose 1.6-bisphosphatase & 50 & $<1$ & 50 & Gancedo \& Gancedo 1971 \\
\hline Isocitrate lyase & 10 & $<0.2$ & 50 & Eraso \& Gancedo 1984 \\
\hline Galactokinase $^{a}$ & 40 & 1 & 40 & Torchia et al. 1984 \\
\hline Glutamate dehydrogenase (NAD) & 190 & 7 & 25 & Polakis \& Bartley 1965 \\
\hline Aconitase & 935 & 170 & 5 & Polakis \& Bartley 1965 \\
\hline Cyst $c$ oxidase & 11 & 2 & 5 & Eraso \& Gancedo 1984 \\
\hline Isocitrate dehydrogenase (NAD) & 75 & 18 & 4 & Polakis \& Bartley 1965 \\
\hline
\end{tabular}

a Relative values are given.

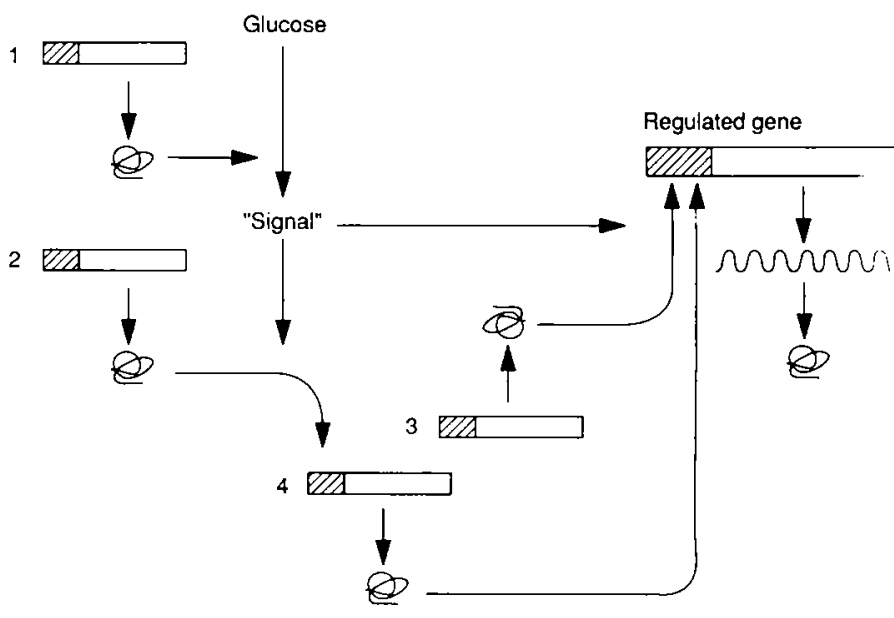

Fig. 1. Simplified scheme for the regulation of a gene subject to catabolite repression. Genes $1,2.3$ and 4 are trans-acting genes implicated at different levels in the control of the regulated gene. The product of gene 1 is necessary for the formation of the signal derived from glucose. This signal interacts with the products of genes 2 and/ or 3 and slows down the transcription of the regulated gene either by activation of repressing proteins or by inhibition of activating proteins. In the first case the products of genes 3 and 4 are transcriptional inhibitors and the signal activates the product of gene 3 and/or activates the transcription of gene 4 . In the second case the products of genes 3 and 4 are transcriptional activators and the signal inhibits the product of gene 3 and/or inhibits the transcription of gene 4 . Hatched boxes represent the promoter regions of the corresponding genes.

protein. Trans-acting regulatory genes affecting catabolite repression could act at different levels as shown on Fig. 1: they could code for proteins involved in the formation of the signal (gene 1), for proteins which interact with other regulatory genes (gene 2) or for proteins which interact with the regulated gene itself (genes 3 or 4 ).

\section{THE SIGNAL}

Catabolite repression can be exerted not only by the three related sugars glucose, mannose and fructose, but also by other types of sugars like galactose (Polakis and Bartley, 1965) or maltose (Eraso and Gancedo, 1984). The fact that some genes are repressed by all these sugars while others are only affected by glucose should be taken into account in any discussion about the signal involved in catabolite repression. At least two possibilities may be contemplated: (a) glucose produces different signals, each of them specific for a certain set of genes, while maltose or galactose produce or mimick only some of these signals and therefore affect only a limited set of genes; (b) all sugars produce only one (and the same) signal but galactose or maltose produce a weaker signal than glucose and only a limited set of genes respond to this weaker signal.

By analogy with the situation in $E$. coli, it was thought that the signal produced by the repressing sugars was a decrease in the concentration of internal cAMP. However several lines of evidence indicate that, in yeast, catabolite repression is not associated with a low level of cAMP. In a mutant permeable to CAMP, the addition of exogenous cAMP did not prevent glucose repression of galactokinase synthesis (Matsumoto et al., 1982) and in different yeasts intracellular concentrations of cAMP are higher in the presence of glucose and other sugars than in derepressed conditions (Eraso and Gancedo, 1984). Results from strains lacking adenylate cyclase suggest that, in $S$. cerevisiae, cAMP itself does not play a critical role in catabolite repression (Matsumoto et al., 1983a) although cAMP may be necessary for the transcription of certain genes like SUC2 (Matsumoto et al., 1984). However, cAMP appears to be specifically involved in the transcriptional repression of the gene $A D H 2$ encoding alcohol dehydrogenase II. Transcription of this gene is dependent on the presence of the active form of the transcription activator ADR1. Phosphorylated ADR1 is inactive and therefore alcohol dehydrogenase II 
derepression is impaired in $b c y I$ mutants where the protein kinases encoded by TPKI or TPK2 are always active (Cherry et al., 1989). In contrast, alcohol dehydrogenase II partially escapes glucose repression in a cyr I mutant having a temperature-sensitive adenylate cyclase (K. Dombek, cited in Taylor and Young, 1990). Since this situation is the opposite of that of $S U C 2$, which cannot be derepressed in such a mutant, it may be concluded that $\mathrm{cAMP}$ does not have a uniform effect on different genes subject to catabolite repression.

In Schizosaccharomyces pombe catabolite repression could also in some cases occur through a cAMP-signaling pathway. In $S c h$. pombe mutants affected in the gene git 2 encoding adenylate cyclase, the gene $f b p l$ encoding fructose 1,6-bisphosphatase is derepressed in the presence of glucose and external cAMP abolishes this derepression. However the derepression is observed even with git 2 alleles which do not cause a marked change in steady-state cAMP levels (Hoffman and Winston, 1991). The reason for the absence of repression in these particular git 2 mutants is not entirely clear.

The use of glycolytic mutants (Gancedo J. M., unpublished results) and of non-metabolizable glucose analogues (Witt et al., 1966; Gancedo and Gancedo, 1985) indicates that extensive metabolism of the sugar is not necessary for the 'glucose signal' to be produced. The only requirement appears to be the presence of a kinase able to phosphorylate the sugar, and this suggests a possible role for glucose 6-phosphate. However, it should be taken into account that a functional kinase is not only required for phosphorylation but also controls the transport of the corresponding sugar (Bisson and Fraenkel, 1983). Therefore, it remains possible that the lack of catabolite repression in the absence of a kinase is related to an alteration in the binding of the sugar to the membrane rather than to the absence of phosphorylation itself. Up to now, no clear evidence exists on the nature of the signal(s) produced by glucose.

\section{THE INTERMEDIARY ELEMENTS}

These elements are the products of the trans-acting regulatory genes which have been introduced in the second section. The existence of these intermediary elements has been revealed by studies on mutants affected in catabolite repression. These mutants belong to two basic types, non-repressible and nonderepressible (for a review see Gancedo and Gancedo, 1986; Entian, 1986). A large number of such mutants has been isolated by different groups and that raised the problem of establishing which mutations were allelic, since their properties were often similar. Comparison between mutants is further complicated by the fact that the effect of a specific mutation depends in some cases on the genetic background. Cloning and sequencing of the corresponding genes in the last few years has allowed a definite identification of many of the mutations which have been reported. It was found that some of them had been isolated in more than one laboratory and named differently, adding confusion to the complexity of the field. An agreement on a unified nomenclature for catabolite repression mutants, as was reached for mutants related with general amino acid control (see Thireos et al., 1984), is extremely desirable. The time is probably ripe for such an initiative since in a number of cases the mode of action of the products of the implicated genes is, at least partially, understood.

Tables 2 and 3 present a list of mutations which, judged by their chromosomal localization or by comparison of the
Table 2. Mutations which interfere with the derepression of certain genes in Saccharomyces cerevisiae. References for each mutation are given in the text

\begin{tabular}{lll}
\hline $\begin{array}{l}\text { Name of the } \\
\text { mutation }\end{array}$ & $\begin{array}{l}\text { Chromosomal } \\
\text { location }\end{array}$ & $\begin{array}{l}\text { Size of the protein } \\
\text { coded by the gene }\end{array}$ \\
\hline & & $\mathrm{kDa}$ \\
cat1 =ccr1 = snf1 & IV, distal to rna3 & 72 \\
cat3 = snf4 & - & 36 \\
hap2 & VII, proximal to ade5 & 29 \\
hap3 & - & 16 \\
hap4 & - & 62 \\
snf2 & XV & 194 \\
snf5 & II & 102 \\
snf6 & - & 58 \\
msn1 & - & 43 \\
\hline
\end{tabular}

sequence of the corresponding genes, are non-allelic. In the following I will review the characteristics of the genes involved in catabolite repression whose products have been characterized to some extent. I will utilize in each case the designation given by the group that first described the mutation; "synonyms' appear in Tables 2 and 3 and in brackets in the text when the mutation is mentioned for the first time.

\section{Intermediary elements necessary for derepression}

CATI (CCRI, SNFI), CAT3 (SNF4)

The products of the genes $C A T I$ and $C A T 3$ appear to act together. Catl mutants were isolated as unable to grow on glycerol or maltose (Zimmermann et al., 1977) or on ethanol (Ciriacy, 1977); in the latter case the mutation received the name $\operatorname{ccr} 1$. Later cat 3 and additional cat 1 mutants were isolated by Entian and Zimmermann (1982). Mutants snfl and snf4, isolated originally as unable to ferment sucrose or raffinose (Neigeborn and Carlson, 1984), were found to be allelic to catl and cat 3 , respectively.

$C A T 1$ encodes a protein of 633 amino acids with 14 histidine residues between positions 18 and 32 (Celenza and Carlson, 1986). This histidine tract is, however, dispensable for function (Celenza and Carlson, 1989). The protein contains a region with similarity to the catalytic domains of mammalian protein kinases and to the product of the yeast gene CDC28. The CAT1 protein can be autophosphorylated, mostly on serine but also on threonine residues (Celenza and Carlson, 1986). The protein kinase activity of CAT1 appears essential for its function since a mutated protein, where a lysine residue in the predicted ATP-binding site is replaced by an arginine, was not functional (Celenza and Carlson, 1989). No physiological substrate has yet been identified for CAT1. Subcellular fractionation experiments suggest that a major part of CAT1 is either associated with membranes or otherwise insoluble (Celenza and Carlson, 1986).

$C A T 3$ encodes a protein of 322 amino acids without conspicuous special features (Schüller and Entian, 1988; Celenza et al., 1989). A CAT3- $\beta$-galactosidase hybrid protein was found in the nuclear fraction (Schüller and Entian, 1988) but was also present in the cytoplasm (Celenza et al., 1989). The effects of the cat 3 mutation can be alleviated by increased dosage of $C A T 1$ or by different mutations in the coding region of $C A T 1$. In this situation $S U C 2$ may be derepressed in the absence of a functional CAT 3 but remains subject to catabolite repression. Therefore it has been concluded that the CAT3 
Table 3. Mutations which eliminate catabolite repression of certain genes in Saccharomyces cerevisiae. References for each mutation are given in the text.

$\begin{array}{lll}\text { Name of the mutation } & \text { Chromosomal location } & \begin{array}{l}\text { Size of the protein } \\ \text { coded by the gene }\end{array}\end{array}$

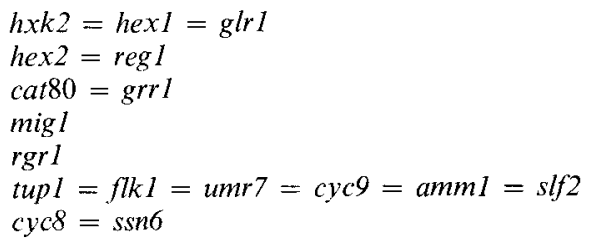

protein affects CAT1 positively without being absolutely required for its function (Celenza and Carlson, 1989). The mechanism of action of CAT3 remains unclear but there is evidence that the proteins CAT1 and CAT3 can interact (Celenza et al., 1989; Fields and Song, 1989). CAT3 appears to function in part by stabilizing CAT1 and this effect is more critical at high temperatures but this is not its major role (Celenza et al., 1989). It has been suggested that CAT3 could directly stimulate the kinase activity of CAT1 or counteract a negative effector of the kinase; another possibility would be for CAT3 to prevent the function of a phosphatase antagonistic to CAT1 (Celenza and Carlson, 1989).

\section{$H A P 2, H A P 3, H A P 4$}

The products of the genes $H A P 2, H A P 3$ and $H A P 4$ appear to act in a concerted manner. Mutants hap2, hap3 and hap4 were identified looking for colonies affected in the expression of the E. coll lac Z gene placed under the control of the UAS2 activating sequence of the gene $C Y C I$ (Guarente et al., 1984; Hahn et a1., 1988; Forsburg and Guarente, 1989). The corresponding genes have been cloned by complementation (Pinkham and Guarente, 1985; Hahn et al., 1988; Forsburg and Guarente, 1989).

$H A P 2$ encodes a protein of 265 amino acids from which a core region comprising amino acids $154-218$ appears sufficient for function in vivo. The region between amino acids 154 and 197 is both necessary and sufficient for association of the protein with the products of $H A P 3$ and $H A P 4$; in this region amino acids $180-184$ appear relatively dispensable (Olesen and Guarente, 1990). The sequence 154-197 shows no similarity with structures previously described for heteromeric protein - protein interaction. The region $197-$ 218 appears essential for DNA-specific binding although it lacks similarity to other structures which bind DNA. The region located from residue 154 towards the amino terminal part increases the transcription rate of the CYC1-lacZ fusion gene but is not absolutely necessary. In this region a polyglutamine tract is located between residues $120-133$. The carboxy-terminal region is highly basic with $27 \%$ of the residues being either arginine or lysine (Pinkham et al., 1987).

The HAP3 gene encodes two overlapping transcripts of 0.57 and $3 \mathrm{~kb}$ that are read off from opposite strands. Using site-directed mutagenesis, it was found that from the possible proteins encoded by $H A P 3$ only a 144 -amino-acid protein encoded by the $0.57-\mathrm{kb}$ transcript is essential for activating transcription (Hahn et al., 1988). The sequence of this protein does not show any characteristic feature. It is not yet clear whether the 3-kb mRNA has any role in $H A P 3$ expression or function.
VII, end link arm

IV, near trpI

$\mathrm{X}$, distal to $c d c 11$

VII, between trp5 and rad6

XII, between gal 2 and pep 3

IV, between $t h r 4$ and $M A L 2$

II, near lys 2

$\mathrm{kDa}$
55
114
133
56
123
78
107

The HAP2 and HAP3 proteins have been tagged by fusion to LexA and $\beta$-galactosidase, respectively. The fusion proteins copurify through four chromatographic steps, indicating that HAP2 and HAP3 can associate in the absence of DNA (Hahn and Guarente, 1988). It has been suggested (Hooft van Huijsduijnen et al., 1990) that the interface between HAP2 and HAP 3 could involve a tetrahedral metal coordination complex between a His-Xaa ${ }_{3}$-His motif from HAP2 and a Cys-Xaa 3 -Cys motif from HAP3. However, since the HAP2 motif is found at positions $196-200$ which are dispensable for HAP2-HAP3 binding (Olesen and Guarente, 1990), the suggestion appears to be incorrect.

HAP4 encodes a protein of 553 amino acids. It contains a very short basic region between residues 54 and 80 , followed by an asparagine-rich tract. The carboxy-terminal region is extremely acidic, $30 \%$ of the residues between $424-471$ and $519-549$ being acidic, and a truncated protein lacking the acidic carboxy-terminal domain is not active. A HAP4-GAL4 fusion protein with residues $1-327$ from HAP4 and the acidic activator region of GAL4 complemented a hap 4 mutation. Therefore it appears that residues $1-327$ allow the anchoring of HAP4 to the complex HAP2-HAP3 and the acidic end is a transcription activation domain (Forsburg and Guarente, 1989).

The three proteins HAP2, HAP3 and HAP4 are required to bind specifically to the corresponding promoters. Using size variants of these proteins, it has been demonstrated that all three are present in the regulatory complex (the presence of additional components has not yet been excluded). Since it appears that the proteins HAP2 and HAP3 are primarily responsible for the site-specific DNA-binding of the complex, the requirement for HAP4 for binding suggests that HAP4 stabilizes the HAP2-HAP3 complex or alters its conformation (Olesen et al., 1987; Forsburg and Guarente, 1989). The HAP4 subunit of the complex would also provide the primary transcriptional activation domain (Olesen and Guarente, 1990).

\section{SNF2 (GAM1), SNF5, SNF6}

The genes $S N F 2, S N F 5$ and SNF6 were identified in a search for mutants unable to ferment sucrose or raffinose (Neigeborn and Carlson, 1984) and their products appear to act in a concerted form. The genes were subsequently cloned by complementation of the phenotype (Abrams et al., 1986; Estruch and Carlson, 1990b). GAMI was described as a gene required for transcription of the $S T A l$ gene which encodes an extracellular glucoamylase of $S$. cerevisiae var. diastaticus. It was then found to be allelic with $S N F 2$ (Yoshimoto and Yamashita, 1991) 
The $S N F 2$ gene encodes a protein of 1703 amino acids with $30 \%$ charged residues and several short acidic and basic regions. Other special characteristics are a glutamine-rich region, a stretch rich in glutamine and alanine residues and nine tandem repeats of the dipeptide arginine-glycine (Laurent et al., 1991; Yoshimoto and Yamashita, 1991). Deletion of SNF2 is not lethal but causes slow growth on glucose; $S N F 2$ is required for growth on raffinose, galactose or glycerol (Laurent et al., 1991).

The SNF5 gene encodes a protein of 905 amino acids with a peculiar composition: of the 270 amino acids between positions 31 and $300,46 \%$ are glutamine; the protein has also three regions with high proline content. However, a deletion of codons 60-296, which removes 110 glutamine and 28 proline residues, does not affect the function of SNF5. Also noteworthy is the high charge of the carboxy-terminal 213 amino acids of the predicted SNF5 protein. There are both a very acidic stretch (net charge -17 over 99 residues) and a basic one (net charge +8 over 44 residues) (Laurent et al., 1990).

The SNF6 gene encodes another highly charged protein of 332 amino acids; the central third of the protein has $45 \%$ charged residues, the number of acidic and basic residues being very similar (Estruch and Carlson, $1990 \mathrm{~b}$ ).

The products of all three genes are localized in the nucleus of the yeast cell (Laurent et al., 1991; Yoshimoto and Yamashita, 1991; Laurent et al. 1990; Estruch and Carlson, $1990 \mathrm{~b}$ ). The nuclear targeting signal of SNF2 could be localized at the carboxy terminus, between residues 1423 and 1554 (Laurent et al., 1991).

The requirement of $S N F 2$, $S N F 5$ or $S N F 6$ for high level $S U C 2$ expression can be obviated by the spt6 mutation. These results suggest a concerted action of the products of the three genes. To examine the mode of action of the gene products, the lexA operator region was fused to a reporter gene and fusions of LexA with SNF2 and SNF5 were constructed. Both fusion proteins activated transcription of the reporter gene (Laurent et al., 1990; Laurent et al., 1991). The activation by the fusion protein LexA-SNF2 is dependent on functional SNF5 and SNF6 genes, while that by the LexA-SNF5 fusion depends on the integrity of $S N F 2$ and $S N F 6$. In this system the requirement for $S N F 2$ or $S N F 5$ but not that for $S N F 6$ could be relieved by the spt6 mutation. These results, together with the findings that overexpression of $S N F 2$ does not abolish the requirement for $S N F 5$ and vice versa and that the double mutant $\operatorname{snf} 2 \operatorname{snf} 5$ does not grow more slowly than the single mutants, suggest that $S N F 2$ and $S N F 5$ play similar, but nonredundant functions. SNF2 and SNF5 could form a complex which binds to DNA but there is no evidence for DNAbinding activity of these proteins. Therefore, if they bind to DNA, they should interact with a factor (or with a family of them) which would provide the DNA-binding capacity and specificity, while both SNF2 and SNF5 would provide the activation domain. SNF6 could affect the SNF2/SNF5 function, either by binding to the complex or through a different mechanism. In any case $S N F 6$ is not required for the expression or nuclear localization of SNF2 or SNF5 (Laurent et al., 1991).

\section{$M S N I$}

Suppression of the temperature-sensitive phenotype of some catl mutants by genes expressed from multicopy plasmids allowed the identification of MSN1. Gene MSN1 encodes a protein of 382 amino acids rich in serine and thre- onine $(17 \%)$ and asparagine and glutamine $(18 \%)$. In addition, the carboxy-terminal region is highly basic (net charge +13 over 78 residues) and appears to be required for function. A LexA-MSN1 fusion protein is able to activate transcription of a gene carrying the LexA operator and an MSN1- $\beta$ galactosidase fusion protein is localized in the nucleus; however, the MSN1 protein synthesized in vitro exhibits only weak, non-specific DNA-binding activity. Therefore, if MSN1 functions as an activator of transcription, it should do so in cooperation with other proteins. A strain carrying a disrupted $M S N 1$ gene has 3-4-fold reduced levels of derepressed invertase. The small effect of the MSN1 disruption on invertase derepression could suggest that other genes function redundantly with $M S N 1$ to affect $S U C 2$ expression and in fact MSN1 probes detect multiple RNAs which could encode partially homologous, functionally redundant proteins (Estruch and Carlson, 1990a).

\section{Intermediary elements necessary for repression}

In the presence of non-metabolizable sugars which act as gratuitous repressors, wild-type yeast does not utilize carbon sources whose utilization requires enzymes sensitive to catabolite repression. Therefore a standard procedure to uncover mutations which abolish catabolite repression has been to look for mutants able to grow on media containing glucosamine or 2-deoxyglucose together with a carbon source like galactose, maltose, raffinose or lactate. In this way many of the following elements were identified.

\section{$H X K 2$ (HEX1, GLR1)}

hex 1 mutants were isolated by Zimmermann and Scheel (1977) and Entian and Zimmermann (1980) and glr $l$ mutants by Michels and Romanowski (1980). They were later found to be allelic to the gene $H X K 2$ encoding the hexokinase isoenzyme P-II (Lobo and Maitra, 1977). This raised the question whether the role of the product of gene $H X K 2$ in the catabolite repression of certain genes depends on its hexokinase activity or is due to a separate regulatory domain. A first set of experiments suggested that there were two domains in hexokinase II and that hexokinase I, the product of $H X K 1$, could not fulfil the same role as hexokinase II (Entian and Frölich, 1984; Entian et al., 1985). However, recent results indicate a strong correlation between catalytic activity of both hexokinases I and II and their capacity to mediate catabolite repression (Ma et al., 1989a, b; Rose et al., 1991). The exact mode of action of HXK2 is still far from understood. The protein appears to possess protein kinase activity (Fernández et al., 1988; Herrero et al., 1989) and this activity could be related with its regulatory function. Since glucose itself is a substrate for hexokinase, it seems plausible that HXK2 be implicated in the production or transduction of the signal for glucose presence. Interestingly glucokinase, another enzyme able to phosphorylate glucose in yeast, does not seem to be able to play the same role as the hexokinases (Rose et al., 1991). Another intriguing observation is the in vivo phosphorylation of both hexokinases, which increases in derepressing conditions (Vojtek and Fraenkel, 1990). This could suggest that the state of phosphorylation of hexokinase II affects glucose repression.

\section{HEX 2 (REGI)}

hex 2 mutations were identified in a search for mutants with non-repressible invertase (Entian and Zimmermann, 1980). It 
was found later (Niederacher and Entian, 1987) that hex2 is allelic to regl, a mutation isolated as conferring resistance to catabolite repression of galactokinase synthesis (Matsumoto et al., 1983b). $H E X 2$ has been cloned by selecting for growth on maltose (Niederacher and Entian, 1987) since hex 2 mutants are unable to grow on maltose, although the reason for this phenotype is still unclear (Entian and Loureiro-Dias, 1990). $H E X 2$ encodes a protein of 1026 amino acids with no distinguishing features except a region with five consecutive serine residues in the middle of an acidic stretch and a further acidic region. There are strong indications for a nuclear localization of the HEX2 protein (Niederacher and Entian, 1991).

\section{$C A T 80(G R R I)$}

cat 80 mutants were isolated by Entian and Zimmermann (1980) and grrl mutants by Bailey and Woodward (1984) and by Flick and Johnston (1991); they appear to be allelic (Niederacher D., cited in Schüller and Entian 1991). CAT80 codes for a large protein of 1151 amino acids which presents as a striking feature 12 tandem repeats of a motif of 26 amino acids rich in leucine and other hydrophobic residues. The protein has a high content of asparagine and leucine residues (11\% and $12 \%$, respectively) and contains 23 potential sites for $\mathrm{N}$-linked glycosylation (Asn-Xaa-Ser/Thr). At both the amino and carboxy ends are stretches rich in asparagine and glutamine. The CAT80 protein appears to be part of a large complex localized in the cytoplasm that sediments at $10000 \times \mathrm{g}$ and is only solubilized by urea. Although its mode of action is unknown, it has been suggested that CAT80 is required for the generation or transduction of the intracellular signal that causes glucose repression (Flick and Johnston, 1991).

\section{$M I G I$}

Screening a yeast library for genes which, in multicopy, would turn off the $G A L I$ promoter under inducing conditions, the $M I G l$ gene was isolated (Nehlin and Ronne, 1990). MIGl encodes a protein of 504 amino acids with two $\mathrm{Cys}_{2} \mathrm{His}_{2}$ zinc finger motifs in the amino-terminal region. There are also several short stretches of glutamine and glutamine alternating with asparagine. By DNaseI footprinting, the MIG1 protein has been found to bind to the promoter of the genes $S U C 2$ (Nehlin and Ronne, 1990), GAL1, GAL4 (Nehlin et al., 1991) and FBPI (Mercado et al., 1991; Ronne H., personal communication). In contrast to the proteins discussed previously, it does not require other proteins to bind DNA (Nehlin and Ronne, 1990; Nehlin et al., 1991). MIG1 appears to act as a repressor of transcription in the presence of glucose; if overexpressed it can even repress transcription of $S U C 2$ in the absence of glucose (Nehlin and Ronne, 1990).

\section{$R G R I$}

$\mathrm{rgrl}$ mutants were isolated as causing overexpression of a reporter gene placed under the control of the $S U C 2$ promoter (Sakai et al., 1988). The mutation has pleiotropic effects: invertase resistance to catabolite repression, reduction in the amount of reserve carbohydrates, defects in sporulation, temperature sensitivity for growth and abnormal cell morphology (Sakai et al., 1988). RGRI encodes a hydrophobic protein of 1082 amino acids with six possible membrane-spanning domains in its sequence. It is essential for growth, since a null $\mathrm{rgrl}$ mutation results in a lethal phenotype. It has been suggested that the RGR1 protein could interact with the RAScAMP pathway (Sakai et al., 1990).

\section{TUP1 (FLK1, UMR7, CYC9, AMM1,SLF2), CYC8 (SSN6)}

Mutations that affect catabolite repression but also present diverse pleiotropic effects, including flocculence, have been isolated by different groups. The mutations tupl and $c y c 8$ relieve catabolite repression for a variety of genes. tup I (Wickner, 1974) is allelic to $f l k 1$ (Schamhart et al., 1975; Stark et al., 1980), to $u m r 7$ (Lemmont, 1977) to $c y c 9$ (Rothstein and Sherman, 1980), to amml (Trash-Bingham and Fangman, 1989) and to $s f l 2$ (Fujita et al., 1990), while $c y c 8$ (Rothstein and Sherman, 1980) is allelic to ssn6 (Carlson et al., 1984) .

The gene TUPI has been cloned (MacKay, 1983; Fujita et al., 1990) and shown to code for a protein of 713 amino acids with long stretches of glutamine and threonine (Williams and Trumbly, 1990; Fujita et al., 1990). The carboxyl third of the predicted TUP1 protein contains six repeats of a pattern of 43 amino acids. The same pattern of conserved residues is seen in the $\beta$-subunit of transducin and in the yeast $C D C 4$ gene product required for progression beyond the G1 phase of the cell cycle. This similarity of the TUP1 protein to subunits of $G$ proteins suggests that the TUP1 repeat domain could be involved in protein - protein interactions. The importance of this region for TUP1 function is indicated by the fact that removal of the 39 carboxy-terminal residues results in a strong mutant phenotype (Williams and Trumbly, 1990).

The gene CYC8 codes for a protein of 966 amino acids with a high proportion of glutamine residues. There are two polyglutamine stretches and a domain of alternating glutamine and alanine residues (Schultz and Carlson, 1987; Trumbly, 1988). The polyglutamine tract near the amino terminus is dispensable, even in the absence of the tracts of polyglutamine and poly(glutamine-alanine) in the middle of the protein. A deletion removing a third of the protein at the carboxy terminus did not cause a severe mutant phenotype (Schultz and Carlson, 1987). The CYC8 protein includes near its amino terminus 10 tandem repeats of a 34-amino-acid sequence which has been named the tetratricopeptide repeat (Sikorski et al., 1990 ). It has been proposed (Hirano et al., 1990) that the tetratricopeptide units form a novel secondary structure, named a 'snap helix', which produces a tightly packed structure and would allow association with similar domains of other proteins. A protein with only three or four tetratricopeptide repeats is still functional but larger deletions abolish function (Schultz et al., 1990). Although the CYC8 protein is localized exclusively in the nucleus the protein lacks consensus domains for DNA-binding proteins and extensive efforts for detecting DNA-binding activity have been unsuccessful (Schultz et al., 1990).

The CYC8 and TUP1 proteins can associate in a highmolecular-mass complex. It is not known how many CYC8 and TUP1 molecules participate in the complex and the presence of other components has not been ruled out (Williams et al., 1991). In relation to the association of CYC8 and TUP1, it should be noted that the TUP1 protein lacks the tetratricopeptide repeat characteristic of CYC8; therefore it would be likely that some other protein(s) form a junction between TUP1 and CYC8. Since overproduction of CYC8 or TUP1 reduces transcription of the $S U C 2$ gene, even in the absence of glucose (Schultz and Carlson, 1987; Williams and Trumbly, 1990), it appears that the complex CYC8/TUP1 plays an inhibitory role on the transcription of $S U C 2$. It would not act, however, directly at the DNA level but through 
Table 4. Catabolite repression mutants not well characterized.

\begin{tabular}{|c|c|c|c|}
\hline Type of mutation & $\begin{array}{l}\text { Name of the } \\
\text { mutation }\end{array}$ & Characteristics & Reference \\
\hline Non-derepressible & $\begin{array}{l}\operatorname{ccr} 2 \\
\operatorname{ccr} 3 \\
\operatorname{ccr} 4\end{array}$ & $\begin{array}{l}\text { non-allelic to cat } 1 \text { or } c c r 3 \\
\text { ChrV, linked to } \operatorname{trp} 2 \\
\text { Chr I, between cys } 3 \text { and cys } 1\end{array}$ & $\begin{array}{l}\text { Ciriacy } 1977 \\
\text { Ciriacy } 1977 \\
\text { Denis } 1984\end{array}$ \\
\hline Non-repressible & $\begin{array}{l}\text { cat } 2 \\
\text { CCR } 80 \\
\text { CCR } 91 \\
\text { cidl } \\
\text { cat4 }\end{array}$ & $\begin{array}{l}\text { epistatic over cat1 } \\
\text { non-allelic with tup } 1, \operatorname{cyc} 8, h x k 2, \text { hex } 1, \text { migl } 1 \\
\text { non-allelic with tup1, cyc8, hxk2, hex2, cat } 80, \text { cidl }\end{array}$ & $\begin{array}{l}\text { Zimmermann et al. } 1977 \\
\text { Ciriacy } 1978 \\
\text { Böker-Schmitt et al. } 1982 \\
\text { Neigeborn \& Carlson } 1987 \\
\text { Schüller \& Entian } 1991\end{array}$ \\
\hline
\end{tabular}

Table 5. Action range of mutations affecting derepression. Abbreviations: ADH II, alcohol dehydrogenase II; FbPase, fructose 1,6-bisphosphatase; + , affects expression of the corresponding gene; - , without effect; \pm , partial effect; nt, not tested.

\begin{tabular}{|c|c|c|c|c|c|c|}
\hline Mutation & \multicolumn{6}{|c|}{ Proteins affected } \\
\hline cat3 & + & + & + & $\mathrm{nt}$ & + & + \\
\hline hap 2, hap 3, hap 4 & - & nt & - & $\mathrm{nt}$ & + & + \\
\hline $\operatorname{snf} 2, \operatorname{snf5}$, snf6 & + & + & + & $\mathrm{nt}$ & $\mathrm{nt}$ & nt \\
\hline
\end{tabular}

interaction with some DNA binding protein. The products of the SNF2, SNF5 and SNF6 genes have been suggested as possible targets (Williams and Trumbly, 1990). Although CYC8 is phosphorylated in vivo (Schultz et al., 1990), the significance of this phosphorylation is not clear.

\section{Other regulatory elements}

Other genes affecting catabolite repression have been described. However, since most of them could be allelic to some of the better identified genes, their status is still uncertain. These genes and their allelic relations, when known, are listed in Table 4. Another set of mutants named $\operatorname{lgn} 1-9$ with pleiotropic effects has been isolated. These mutants are affected in the regulation of repression-derepression of a variety of genes encoding enzymes belonging to the tricarboxylic acid cycle, the electron transport chain and the gluconeogenic pathway (Bisson, 1988). Differences in the background of the wild-type strains precluded complementation tests with snf mutations.

Finally, some genes connected with catabolite repression appear to be specific for a single gene or set of genes. Examples would be $G A L 82, G A L 83$ for genes coding for enzymes of the galactose pathway (Matsumoto et al., 1981) or $A D R 6$ for the $A D H 2$ gene (Taguchi and Young, 1987). $A D R 1$, which was also considered specific for the $A D H 2$ gene, has recently been shown to activate also the transcription of genes encoding peroxisomal proteins (Simon et al., 1991).

\section{Effect of the intermediary elements on the expression of different genes}

As indicated in the introduction, there is a large variety of genes whose expression is regulated by catabolite repression. The different catabolite repression mutants isolated have been identified by their action upon one or another of these regulated genes and their effect on other genes has not been systematically tested. Our knowledge on the role of the intermediary elements in catabolite repression therefore remains very fragmentary. It would be useful to test the effect of the different mutations in as large a number of systems as possible to establish two points: what is the range of action of each intermediary element and what are the elements implicated in the regulation of a given gene? A problem when approaching this goal can be the fact already mentioned that the effects of a mutation on a particular system vary depending on the genetic background of the yeast strain, e.g. catl affects expression of $S U C 2$ in certain strains (Neigeborn and Carlson, 1984) while it has no effect in others (Zimmermann et al., 1977). Tables 5 and 6 summarize which genes have been reported to act on different systems and I will discuss in a later section how the different intermediary elements could interact to regulate specific genes.

It may be worth pointing out that many of the intermediary elements described present either acidic regions or glutamine-rich stretches and one of them, $S N F 5$, has three prolinerich sequences. Although these types of region have been found in protein domains responsible for transcriptional activation (Mitchell and Tjian, 1989), it does not necessary follow that all the intermediary elements featuring these regions are directly implicated in the activation of transcription. It is more likely that these particular regions have the more general role of participating in protein-protein interactions implicated, at different levels, in the control of gene expression.

\section{CIS-REGULATORY ELEMENTS}

In this section I will review the studies performed on the promoters of a variety of genes subject to catabolite repression to try to delineate which sequences are important in mediating 
Table 6. Action range of mutations affecting catabolite repression. Abbreviations as in Table 5 .

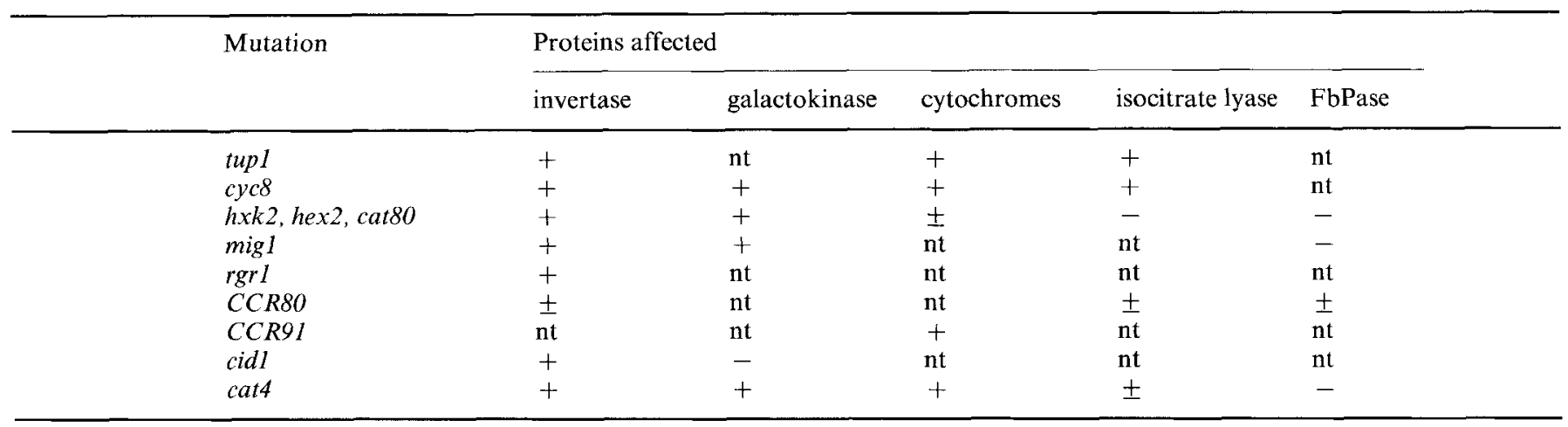

$\mathbf{A}$

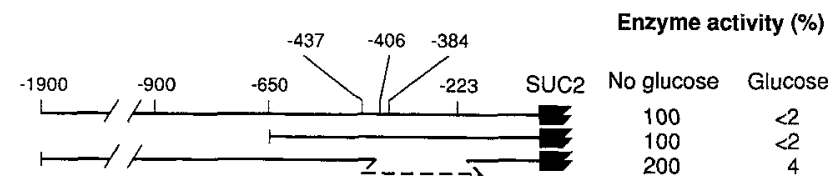

B

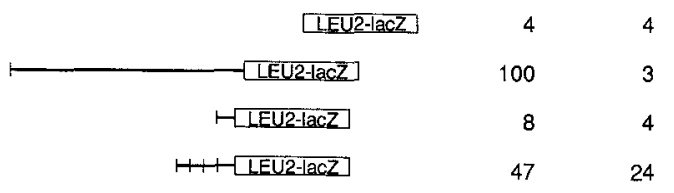

Fig. 2. Effect of different fragments of the $S U C 2$ promoter on the expression of $S U C 2$ and of a $L E U 2$-lac $Z$ fusion. (A) Deletions were performed in the promoter region of the $S U C 2$ gene and invertase was measured in yeast cells containing the different constructions. (B) Fragments of the $S U C 2$ promoter were fused to a $L E U 2$-lac $Z$ gene and $\beta$-galactosidase was measured in yeast cells containing these constructions. The yeasts were grown in the absence or presence of glucose. Enzyme activity is given as a percentage of the activity shown by the constructions with the largest promoter fragment. Adapted from Sarokin and Carlson $(1984,1986)$. For more details see text.

the effect of glucose. In most cases a similar strategy has been utilized, which consists in defining which fragment of the promoter region is necessary to direct the regulated transcription of a reporter gene and, in a second phase, in evaluating the effect on transcription of a variety of deletions in the promoter.

\section{SUC genes}

There is a family of $S U C$ genes coding for invertase but the most thoroughly studied is the gene $S U C 2$. As shown in Fig. 2, sequences upstream of -650 and between -403 and -223 are dispensable for the regulated expression of this gene. A variety of deletions did not reveal any region which could be responsible for direct negative regulation of the $S U C 2$ gene in response to glucose (Sarokin and Carlson, 1984). A fusion of the $-900 /-384$ region with a $L E U 2$-lac $Z$ gene increased lac $Z$ expression about 25 -fold in the absence of glucose but had no effect in its presence. Expression of this fusion was regulated, like that of a normal $S U C 2$ gene, by the transacting genes $C A T 1, S N F 5$ and $C Y C 8$ (Sarokin and Carlson, 1985a). A sequence of 32 bp situated between -437 and -406 activates slightly lac $Z$ expression but the activatory effect is increased when several copies of the 32-bp sequence are placed in tandem. In these constructions expression is little affected by glucose or by the trans-acting genes mentioned (Sarokin and Carlson, 1986).

Within the 32-bp sequence, a 7-bp element has been identified which is repeated with small variations at other places in the upstream-activating region of $S U C 2$. Similar sites are also found in the $S U C 7$ promoter (Sarokin and Carlson, 1985b) and in the promoters of $S U C 1, S U C 3, S U C 4$ and $S U C 5$ (Hohmann and Gozalbo, 1988). The consensus sequence of these sites is $(\mathrm{A} / \mathrm{C})(\mathrm{A} / \mathrm{G})$ GAAAT. The hypothesis that these elements play a regulatory role (Sarokin and Carlson, 1986) is strengthened by the fact that deletions that affect the 7-bp elements also affect $S U C 2$ expression (Sarokin and Carlson, 1984). Moreover a deletion mutant $\Delta-456 /-223$ which had lost two copies of the 7-bp element showed a tenfold decrease in invertase expression. Pseudorevertants of this mutant were obtained and several of them had been mutated in the 7-bp element around position -476 . This particular element did not match exactly the consensus sequence since it had only two adjacent adenine residues. The three different mutations in the pseudorevertants produced sequences with three consecutive adenine residues which were more closely related with the consensus sequence. In the three cases invertase expression was greatly increased and the increase was most marked (36fold) for a mutation which gave a perfect match (Sarokin and Carlson 1986). These results support the significance of the 7-bp repeated elements for $S U C 2$ transcription.

In the $S U C 2$ promoter two sequences have been identified able to bind the product of the regulatory gene $M I G 1$ (Nehlin and Ronne, 1990). The removal of one of the binding sequences has no effect on glucose repression (Sarokin and Carlson, 1984) but the removal of the other has not been attempted. That the binding of MIG1 to at least one of the sites in the $S U C 2$ promoter mediates repression by glucose is suggested by the finding that a mig 1 null mutation makes the synthesis of invertase much less sensitive to catabolite repression (Nehlin and Ronne, 1990). The observation that the 32 -bp sequence from the $S U C 2$ promoter, which is able to activate transcription even in the presence of glucose, does not contain a complete MIG1-binding sequence also supports a regulatory role for this sequence.

\section{$M A L$ genes}

A family of at least five $M A L$ loci exists in Saccharomyces species. Each of the loci comprises two structural genes, which encode maltose permease and maltase respectively, and a regulatory gene encoding an activator of transcription. The $M A L 6$ locus has been studied most thoroughly and upstream and 
internal deletions of the MAL6S gene, coding for maltase, have been generated (Hong and Marmur, 1987). The analysis of these mutations indicates that a T-rich region at position -253 to -237 relative to the MAL6S ATG initiation codon may be involved in catabolite repression since removal of this region increases activity under repressing conditions up to fivefold. An examination of the MAL6S promoter sequence (Hong and Marmur, 1986) shows that there are at least two sites with a sequence similar to the consensus sequence for binding the regulatory protein MIG1 (Griggs and Johnston, 1991; Nehlin et al., 1991). As in the case of the SUC2 gene removal of one of these sequences has no effect on glucose repression (Hong and Marmur, 1987) and removal of the other one has not been performed.

\section{$G A L$ genes}

Two different approaches have been used to look for sequences in the $G A L$ genes which could be responsible for glucose repression. In one approach gene fusions containing whole promoters were constructed, most often GALI-lacZ or $G A L 10-$ lacZ, and the effect of progressive and internal deletions upon glucose repression of the transcription was tested. In the other approach different fragments of a $G A L$ gene promoter were ligated to a hybrid gene which had a functional upstream activating sequence insensitive to glucose. The first approach showed that the deletion of a region of $160 \mathrm{bp}$ from the GAL1 promoter lowered glucose repression by a factor of $15-30$. This deletion, however, also allowed a significant constitutive transcription (that is, independent of induction by galactose) and it was not clear whether these effects result from a decrease in the distance between an upstream activating sequence $\mathrm{UAS}_{\mathrm{G}}$ and the TATA box or from the removal of specific sequences able to bind negative regulatory proteins (West et al., 1984). The second approach allowed the identification of specific sequences able to mediate negative control by glucose. The degree of repression conferred by these sequences was relatively low, from 5-fold (Struhl, 1985) to 30-fold (Flick and Johnston, 1990). Although one of the negatively cis-acting sites, URS-A (Flick and Johnston, 1990), binds the regulatory protein MIG1 (Nehlin et al., 1991), the role of these sites in mediating catabolite repression in the intact genes is probably marginal (see next section).

\section{Genes coding for elements of the respiratory chain}

To map the site(s) responsible for catabolite repression in the gene $C Y C 1$, encoding the iso-1-cytochrome $c, C Y C 1$-lac Z fusions have been constructed. A truncated promoter extending from position -229 to -178 was sufficient to direct transcription repressed by glucose (Guarente et al., 1984). The corresponding upstream activating sequence was named UAS2. Activation by this sequence depends on the presence of the trans-acting genes $H A P 2, H A P 3$ and $H A P 4$ (see earlier section). In a gel retardation assay, the fragment -263 to -173 of the CYCI promoter, which contains the UAS2 sequence, formed three distinct protein-DNA complexes (Olesen et al., 1987). One of them was found only in derepressed conditions and in this complex the protein made contacts within a consensus TN(A/G)TTGGT sequence. This sequence is found in different promoters (CYC1, HEM1, COX4 etc.) controlled by HAP2, HAP3 and HAP4 (Maarse et al., 1988; Calder and McEwen, 1990). A mutation in the wild-type $C Y C 1$ promoter which changed the third base in the regulatory element from $\mathrm{G}$ to $\mathrm{A}$ increased transcription; the mutated sequence was called UP1 element (Olesen et al., 1987). The UAS2 site from $C Y C 1$ has been further analyzed in constructions with CYC1-lac $Z$ fusions activated by the wild-type or the UP1 form of UAS2 (Forsburg and Guarente, 1988). Sequences upstream of -230 appear dispensable. Although $3^{\prime}$ deletions up to -200 maintain still a significant expression regulated by glucose, sequences between -190 and -178 are necessary for maximal expression. A short dyad GCTCN ${ }_{7}$ GAGC between positions -227 and -213 could be important for transcription since a $3^{\prime}$ deletion destroying the consensus and all downstream sequences but leaving the dyad intact has a weak activity induced by lactate. Therefore within UAS2 two regions have been defined: region 1 from -229 to -200 , which mediates catabolite repression and which includes the dyad and the consensus binding site for HAP2/ HAP3/HAP4, and region 2 from -190 to -178 which increases the activating effect of region 1.

\section{$A D H 2$}

Transcription of the $A D H 2$ gene, which encodes the alcohol dehydrogenase II used for catabolizing ethanol, is repressed in cells grown on glucose (Denis et al., 1981). Initial experiments suggested that it was possible to perform a deletion in the promoter in such a way that catabolite repression would be eliminated (Beier and Young, 1982); however, further studies have shown that the rate of transcription changed markedly when different regions of the promoter were removed but that glucose repression was maintained in all cases (Beier et al., 1985; Yu et al., 1989).

\section{$F B P 1$}

The gene $F B P 1$ encoding fructose 1,6-bisphosphatase is also controlled by catabolite repression. Deletion analysis allowed the identification of a region of the promoter which could be involved in the repression by glucose. When the region from -480 to -170 was deleted, the repression factor decreased from 140 -fold to about 2 -fold while the maximal level of expression was reduced by less than 4-fold (Mercado et al., 1991). In the regulatory region three sites potentially able to bind the regulatory protein MIG1 have been identified; in foot-printing experiments two of them have been found to bind nuclear proteins (Mercado et al., 1991).

\section{INTEGRATION OF THE DIFFERENT ELEMENTS}

The final goal in the study of catabolite repression is to understand how the different elements of the system interact to produce the changes in transcription observed in the presence and absence of glucose. A point that has become clear as our knowledge has increased is that the mechanisms of regulation are not identical for different genes. Therefore we will consider the mechanisms of regulation of a small number of genes for which substantial information is available.

\section{Regulation of the $S U C 2$ gene}

The gene SUC2 coding for invertase has been most thoroughly studied. Since it does not require induction by a carbon source, its regulation appears less complex than that of other genes; nevertheless, a bewildering number of transacting factors are involved in $S U C 2$ control. We have already described the products of the genes $C A T 1, C A T 3, S N F 2$, 
Table 7. Epistatic relations between different mutations affecting $S U C 2$ transcription. Invertase activity is expressed in a semiquantitative manner, - indicating no activity and ++++ maximal activity.

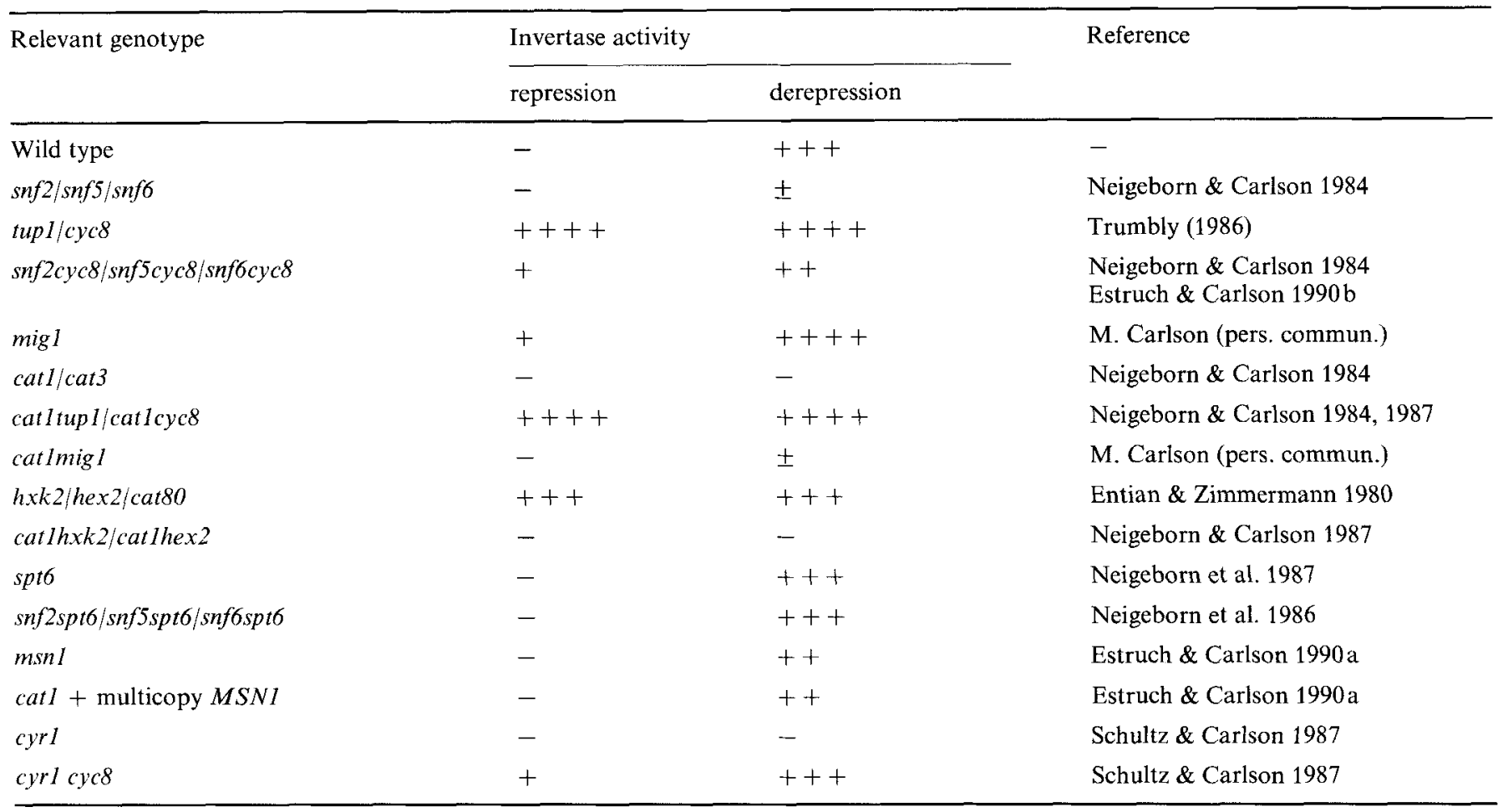

SNF5, SNF6 and MSNI which are required for maximal derepression to take place and the products of the genes $H X K 2, H E X 2, C A T 80, T U P 1, C Y C 8, M I G 1, R G R 1$, which are necessary for repression to occur. Further genes like CCR80, CID1 and CAT4 could also play a role (see Table 4). To establish the level at which the different genes act, epistatic relationships, that is the effects of double mutations on $S U C 2$ transcription, have been studied with the results shown in Table 7. From these data and from the biochemical features of the products of trans-acting genes (see earlier section) the following conclusions can be deduced.

a) The complex SNF2/SNF5/(SNF6) appears to play a direct role in the activation of $S U C 2$ transcription. The fact that there is no evidence for the binding of SNF2 or SNF5 to the DNA suggests that the complex could act as a transcriptional adaptor (Berger et al., 1990) or a mediator (Flanagan et al., 1991) between the RNA polymerase II complex and a still unidentified, DNA-binding, activating factor X.

b) SPT6, an essential gene which appears to affect chromatin structure (Swanson et al., 1990), would maintain the DNA in a tight conformation which requires activators for transcription to take place. In spt6 strains $S U C 2$ can be expressed in the absence of $S N F 2, S N F 5$ or $S N F 6$ or when large regions of the $S U C 2$ promoter have been removed (Neigeborn et al., 1987). In this later case the expression is only slightly affected by glucose $(2-4$-fold) unless there is an MIG1-binding region in the promoter (in these conditions glucose repressed about 25 -fold). This, in turn, suggests that the negatively acting DNA-binding protein MIG1 is able to respond to the presence of glucose.

c) $M S N 1$, which is not absolutely required for $S U C 2$ transcription, would only increase the rate of $S U C 2$ expression. It would operate only in the absence of glucose, since $M S N 1$ in multicopy can bypass the requirement for $C A T 1$ for $S U C 2$ expression but does not overcome catabolite repression. d) Next in the hierarchy would be the complex CYC8/ TUP1, since $c y c 8$ is only partially epistatic over $s n f 2, s n f 5$, snf6 but $c y c 8$ and tupl are epistatic over cat1. CYC8/TUP1 would inhibit $S U C 2$ transcription since in $c y c 8$ or tupl mutants $S U C 2$ is transcribed at a high rate independently of the carbon source present.

e) CAT1 and CAT3 would exert their action by modification of CYC8/TUP1.

f) The products of the genes $H X K 2, H E X 2$ and $C A T 80$ would act further upstream, probably signaling the presence of glucose to CAT1 and CAT3.

This would result in the model shown in Fig. 3. Glucose, in the presence of the proteins HXK2, HEX2 and CAT80, displaces the equilibrium between active and inactive CAT1/ CAT3 complexes towards the inactive form. In the absence of glucose, CAT1/CAT3 is in an active form and inactivates the complex CYC8/TUP1, perhaps through phosphorylation. Inactivation is not complete, however, since expression of SUC2 is higher in $c y c 8$ or tup 1 mutants than in a derepressed wild-type strain. A dominant mutant of CAT1, CAT1-2d (Zimmermann et al., 1977), which causes a less tight repression, would code for a protein permanently active.

The rate of $S U C 2$ transcription depends on a balance between activation by MSN1 and X (together with SNF2, SNF5, SNF6) and inhibition by MIG1. The complex CYC8/ TUP1 could both facilitate binding and/or increase activity of the inhibitory factor MIG1 and interfere with the binding and/or activity of the activating factor $X$.

One possible mode of action for glucose would be to affect the transcription of some of the regulatory genes; however, the results available indicate that the steady-state levels of the products of CAT1 (Celenza and Carlson, 1984), CAT3 (Schüller and Entian, 1987), SNF2, SNF5 (Abrams et al., 1986), SNF6 (Estruch and Carlson, 1990 b), HXK2 (Gancedo et al., 1977), HEX2 (Niederacher and Entian, 1991), CAT80 


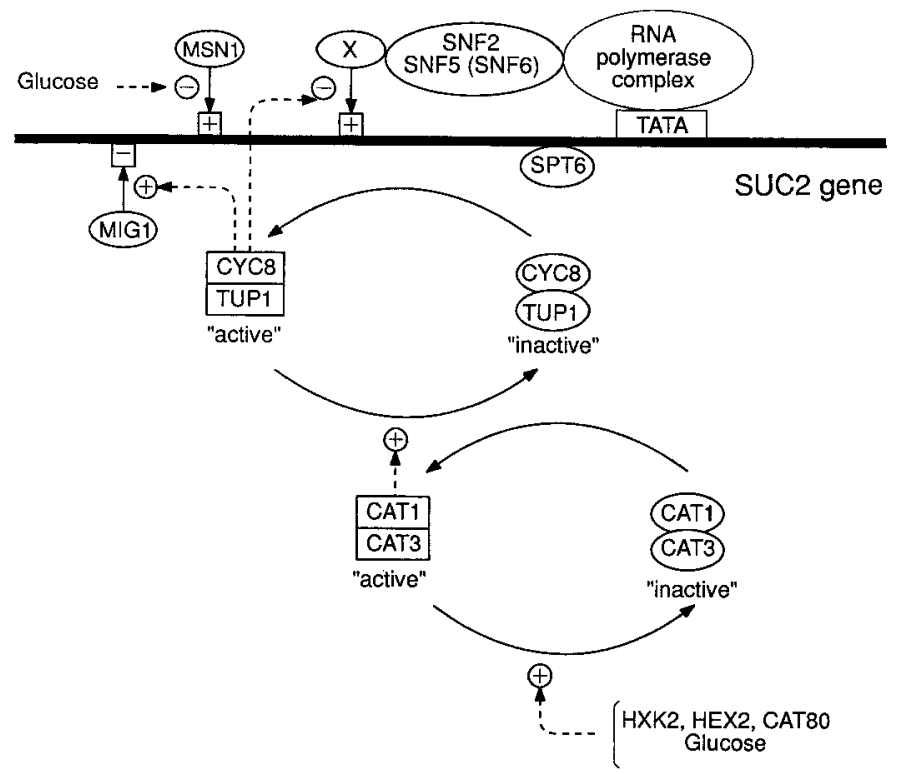

Fig. 3. A simplified model for the regulated expression of the $S U C 2$ gene. In the absence of glucose, $S U C 2$ is transcribed due to the activating effects of the proteins MSN1 and $\mathrm{X}$ and to the action of the mediator complex SNF2/SNF5/(SNF6). In the presence of glucose, the proteins HXK2, HEX2 and CAT80 favour the formation of the inactive form of the complex CAT1/CAT3. When this complex is inactive, the CYC8/TUP1 complex is active and it facilitates the binding and/or activity of the inhibitory factor MIG1. At the same time it inhibits the binding and/or activity of the activator X. MSN1 is down-regulated by glucose independently of CAT1. These different controls result in a decreased transcription of $S U C 2$ in the presence of glucose. For more details and the role of SPT6 see text.

(Flick and Johnston, 1991), CYC8 (Schultz and Carlson, 1987), TUPI (Williams et al., 1991) and MIGI (Nehlin and Ronne, 1990) are independent of the presence or absence of glucose in the growth medium. Therefore glucose is more likely to act by modifying the activity of one or more of the regulatory gene products by a mechanism hitherto undefined. In any case, glucose does not operate exclusively through CAT1 and CYC8, since mutants like catl with multicopy $M S N 1$ or $\operatorname{sif} 2 c y c 8$ and $c y r l c y c 8$ can still be repressed by glucose, at least partially (Table 7).

The model presented in Fig. 3 is a simplification since regulatory proteins with an undefined position in the control hierarchy (like RGR1 and probably others) have been omitted and pieces of the puzzle may still be missing. For instance, the role of CCR4, an activating factor negatively regulated by SPT6 (Denis and Malvar, 1990), in SUC2 transcription has not been examined. That cAMP plays some role in the repression of $S U C 2$ can be deduced from the fact that $c y c 8$ partially suppresses a cyr 1 mutation and from the recent observation that overexpression of the CDC25 gene suppresses repression of invertase by glucose (Van Aelst et al., 1991). CDC25 is involved in the activation of adenylate cyclase by the RAS1 and RAS2 proteins but it is not yet clear how to integrate the above findings in the model for $S U C 2$ regulation.

Still additional types of regulatory mutants have been described. Mutation $\operatorname{snf} 3$ was isolated in a screen for sucrose non-fermenting mutants (Neigeborn and Carlson, 1984) but later $S N F 3$ was shown to code for a glucose transporter which does not affect $S U C 2$ expression (Neigeborn et al., 1986; Celenza et al., 1988). Recently a new mutation, ccs I, linked to $S N F 3$ has been identified. Although $c c s I$ mutants express invertase normally, $\operatorname{css} 1 \operatorname{snf} 3$ double mutants express invertase constitutively at a level intermediate between those of the repressed and derepressed wild-type cells (Marshall-Carlson et al., 1990). It has been suggested that CCS1 could encode a second glucose transporter or a regulator of a glucose transporter.

\section{Regulation of the $G A L-M E L-L A C$ genes}

In $S$. cerevisiae the genes required for the utilization of galactose and melibiose ( $G A L 1, G A L 2, G A L 7, G A L 10$, $M E L 1)$ are induced by galactose and repressed by glucose (Adams, 1972; for reviews see Oshima, 1982; Johnston, 1987). In Kluyveromyces lactis the genes required for the utilization of galactose and lactose $(G A L 1, G A L 7, G A L 10, L A C 4$, $L A C 12$ ) are also induced by galactose (Riley and Dickson, 1984) but the repressing effect of glucose is not very pronounced and varies between different isolates (Breunig, 1989). Although the mode of action of glucose has not yet been elucidated, much information has accumulated in the last few years about the elements involved in the regulatory circuits governing catabolite repression of these genes in $S$. cerevisiae.

Transcription of the $G A L / M E L$ genes requires the $G A L 4$ gene (Douglas and Hawthorne, 1966; Hopper et al., 1978; Johnston and Hopper, 1982; Laughon and Gesteland, 1982; Hashimoto et al., 1983), which encodes a positive control protein able to bind to a number of related $17-\mathrm{bp}$, dyadsymmetric sequences which are found in 1-4 copies in the promoters of the different genes (Giniger et al., 1985). A negative regulatory protein GAL80 can interact with the GAL4 protein (Douglas and Hawthorne, 1966; Nogi et al., 1984; Yocum and Johnston, 1984), in such a way that the complex GAL4-GAL80, although still able to bind at the specific DNA sites in the promoter, can no longer activate transcription. Since gal80 mutants do not require galactose for expression of the $G A L$ genes, it has been concluded that galactose acts as an inducer of transcription by counteracting the inhibitory effect of GAL80. The mechanism of action of the galactose is not clear but it requires the product of the gene $G A L 3$, at least for rapid induction (Torchia and Hopper, 1986). Since $G A L 3$ encodes a protein very similar to galactokinase (Bajwa et al., 1988) and a gal3 mutation can be suppressed by the $G A L 1$ genes from $S$. cerevisiae or from $K$. lactis (Meyer et al., 1991), the role of GAL3 could be to catalyze the synthesis of an inducer from galactose. The inducer, however, would not be Gal-1-P itself since galactokinase from $E$. coli, which is catalytically active in yeast, cannot restore normal induction in a gal3 mutant (Bhat et al. 1990). It has been suggested that the inducer would bind to GAL80 but that has not yet been proven.

As shown in schematic form in Fig. 4, glucose could block transcription either by facilitating the binding to the promoter of negative regulatory proteins or by interfering with the activation by GAL4. This interference could take place at different levels: glucose could affect the synthesis of GAL4, its binding to DNA and the activation of transcription or it could antagonize the action of galactose. Strains lacking the protein GAL80 no longer require galactose as inducer, although they are still dependent on GAL4 for activating transcription. In such strains repression of $G A L 1$ by $2 \%$ glucose varies from 15-fold to 170-fold (Nehlin et al., 1991; Torchia et al., 1984; Griggs and Johnston, 1991) in comparison with the 80-600fold repression observed in wild-type strains grown in the presence of a mixture of glucose and galactose (Nehlin et al., 


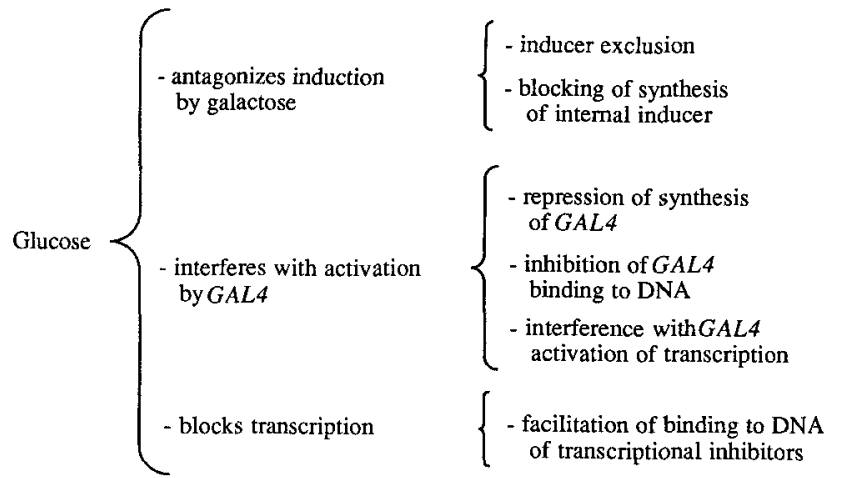

Fig. 4. Possible modes of action of glucose to repress expression of the $G A L-M E L$ genes.

1991; Finley et al., 1990). Thus it is clear that glucose interferes with galactose induction, a possible mechanism being inducer exclusion and another inhibition of the formation of the internal inducer by GAL3 (see Johnston, 1987, for a more thorough discussion). In addition, glucose has also a very marked effect in gal80 mutants where galactose induction is not required.

Ultraviolet footprinting in vivo has been used to study DNA - protein interactions in the GALI-GALIO upstream activating sequences (Selleck and Majors, 1987). It has been observed that GAL4-dependent photofootprints are lost under conditions of catabolite repression and that no footprint patterns characteristic of catabolite-repressed cells could be identified. These results suggest that glucose acts by interfering with GAL4 activation rather than by facilitating the binding of a negative regulatory protein to the promoter. Very recent results indicate that the effect of glucose is mainly mediated through the control of GAL4 synthesis, since in a gal80 strain which expresses $G A L 4$ constitutively, catabolite repression decreases to 4-fold as compared with 170-fold (Griggs and Johnston, 1991). It has also been reported that in a GAL8O background overexpression of GAL4 abolishes glucose repression, although a small degree (5-fold) of induction by galactose is maintained (Martegani et al., 1990).

Regarding the control of GAL4 transcription itself by glucose, it has been shown that glucose causes a modest repression (4-7-fold) of the corresponding gene and that this repression is mediated by promoter sequences which bind the regulatory protein MIG1 (Griggs and Johnston, 1991; Nehlin et al., 1991). The relatively small decrease in GAL4 concentration caused by glucose seems largely responsible for the changes in GALI transcription (Griggs and Johnston, 1991). In the double mutant gal80migl repression of $G A L 1$ by glucose is reduced to a mere 2-fold (Nehlin et al., 1991) indicating that the residual level of repression due to the interaction of negative regulatory proteins (other than MIG1) with the promoter of $G A L 1$ is very low. It should be noted that MIG1 is able to bind to the promoter of GALI (Nehlin et al., 1991) but the low level of repression in a gal80 strain with constitutive GAL4 (see above) suggests that the main role of MIG1 is at the level of GAL4 transcription and that there are no other significant negative regulators of the $G A L 1$ promoter.

This is somewhat in contrast with results obtained with an element of the $G A L 1$ promoter which has been called $\mathrm{URS}_{\mathrm{G}}$ and which conferred repression by glucose (independent of GAL4) to a hybrid promoter (Flick and Johnston, 1990). It is possible that in the intact $G A L 1$ promoter the effect of this negative element is overriden by activation driven by GAL4. In fact the regulation of yeast $G A L$ genes seems to depend on a balance between the function of positive and negative control elements (West et al., 1987; Finley et al., 1990). In any case, the control of the $G A L$ genes is exceedingly complex since a whole series of trans-acting genes is also involved in glucose repression. We already cited the $M I G l$ gene, whose role in regulating GAL4 expression appears well established, but at least six other genes have been identified which are required for repression of the $G A L$ genes. Mutations in any of the genes HXK2 (Zimmermann and Scheel, 1977; Entian, 1980; Ma and Botstein, 1986), $H E X 2$ (Matsumoto et al., 1983 b; Neigeborn and Carlson, 1987), GAL82, GAL83 (Matsumoto et al., 1981, 1983 b, GRRI (Bailey and Woodward, 1984) or CYC8 (Schultz and Carlson, 1987) causes a decrease in glucose repression. However the mode of action of these genes is unknown. It has recently been reported that there are different forms of the GAL4 protein and it has been proposed that changes in its phosphorylation state could modulate its activity (Mylin et al., 1989). A possibility would be that these changes are mediated by the products of the genes GAL82 and GAL83 which appear specific to galactose metabolism and that catabolite repression in turn depends on modifications of the GAL4 protein. Another role for the products of some of the transacting genes could be to participate in the formation of the 'signal' produced by glucose. In relation to this signal, interesting observations have been made (Torchia et al., 1984): the system is not saturated at $2 \%$ glucose, in a gal 80 mutant the residual expression of $G A L 1$ observed at $2 \%$ glucose disappears at $10 \%$ glucose; in addition, in a gal 80 mutant, galactose can 'self-catabolite repress' the expression of the galactosemelibiose pathway genes by a factor of 2 . We are still too ignorant to interpret these properties of the system but they should be taken into account to propose a sensible model for the mode of action of glucose.

As a final point it should be indicated that expression of the $G A L$ genes, as occurs with other genes subject to catabolite repression, is dependent on the products of the genes CAT1, CAT3, SNF2, SNF5, SNF6 (Neigeborn and Carlson, 1984). The mode of action of the corresponding proteins has not yet been elucidated, but a model similar to that proposed for $S U C 2$ (Fig. 3) could be considered for the regulation of GAL4 transcription.

\section{Regulation of the $A D H_{2}$ gene}

Transcription of the $A D H 2$ gene is activated several hundredfold in glucose-free medium (Ciriacy, 1975; Denis et al., 1981). Full derepression of the gene requires the product of ADR1 (Ciriacy, 1975; Denis et al., 1981; Denis and Young, $1983)$ and a number of other proteins such as the products of CAT1 (CCRI), CCR2, CCR3 (Ciriacy, 1977), CCR4 (Denis, 1984) and ADR6 (Taguchi and Young, 1987). $A D H 2$ expression partially escapes glucose repression in some $A D R I$ mutants like $A D R 1-5^{c}$ (Ciriacy, 1979) and in crel and cre 2 mutants (Denis, 1984).

Two different pathways appear to control the expression of the $A D H 2$ gene. One of them is dependent on the transcriptional activator $A D R I$ which binds to a 22-bp inverted repeat upstream of the TATA element (Shuster et al., 1986). The other one depends on CCR4 and does not require sequences upstream of the TATA element for activating transcription (Denis and Malvar, 1990). Both pathways are subject to repression by glucose (Denis, 1984; Blumberg et al., 1988) but the mode of action of glucose on the CCR4 pathway is un- 
known. Apparently the products of the genes $C R E 1$ and $C R E 2$ (allelic to SPT6 and SPT10; Denis and Malvar, 1990) act as negative effectors in this pathway. With regard to the $A D R I$ pathway, it has been observed that $A D R I$ mRNA levels are not repressed by glucose and that the $A D R 1-5^{c}$ mutation which increases $A D H 2$ expression 60 -fold during glucose repression involves the modification of a sequence of the ADR1 protein which is usually recognized by cAMP-dependent protein kinases (Denis and Gallo, 1986). The fact that ADR1 is phosphorylated in vitro by a cAMP-dependent protein kinase, that increased kinase activity in vivo inhibits $A D H 2$ expression and that the degree of inhibition depends on the $A D R I$ allele present, support the idea that glucose repression of $A D H 2$ is mediated, at least in part, by cAMP-dependent phosphorylation of ADR1 (Cherry et al., 1989). Phosphorylation of ADR1 has no effect on its specific binding to DNA; therefore it has been suggested that phosphorylation prevents the interaction of ADR1 with other transcription factors or with RNA polymerase II itself (Taylor and Young, 1990). The activation of ADR1 during derepression could be mediated by a protein phosphatase which, in turn, could be regulated by the protein kinase CAT1 which has been shown to be necessary for ADR1 to be operative (Denis and Gallo, 1986). If ADR1 is overproduced, $A D H 2$ can be expressed in the presence of glucose at high levels and this expression is not dependent on the CATI gene (Denis, 1987). A possible interpretation of these results is that the system which phosphorylates ADR1 in vivo is saturated at high concentrations of ADR1 and that in these conditions a proportion of the transcription factor remains in the unphosphorylated, active form independent of the activity of CAT1.

The role of ADR6 in any of the circuits is unknown, although the corresponding gene has been shown to encode a protein with a potential $\mathrm{Zn}$ finger of the $\mathrm{Cys}_{4}$ type near its carboxy terminus. This fact, together with the nuclear location of an ADR6- $\beta$-galactosidase fusion protein, suggest that ADR6 is a direct activator of $A D H 2$ transcription (O'Hara et al., 1988). $A D R 6$ appears to be relatively specific for $A D H 2$ since other enzymes repressed by glucose, like isocitrate lyase and malate dehydrogenase, are derepressed normally in an adr6 mutant (Taguchi and Young, 1987).

\section{Regulation of the $\mathrm{CYC1}$ gene}

Transcription of $\mathrm{CYCl}$ is regulated negatively by glucose and positively by heme. In a heme-sufficient medium transcription is repressed by glucose about fivefold (Zitomer et al., 1979). Repression by glucose is relieved in mutants $c y c 8$ and tupl (cyc9) (Rothstein and Sherman, 1980) as well as in hex2 mutants (Borralho et al., 1989).

Using a CYCl-lacZ fusion gene (Guarente and Ptashne, 1981) it has been established that the complex HAP2/HAP3/ HAP4 is necessary for derepression (Forsburg and Guarente, 1989). While HAP2 and HAP3 are synthesized constitutively (Pinkham and Guarente, 1985; Hahn et al., 1988) HAP4 transcript levels are elevated $4-5$-fold in the absence of glucose (Forsburg and Guarente, 1989). HAP4 could therefore mediate the repression by glucose. It has also been observed that the leader of HAP4 mRNA includes two upstream ATGs which could confer translational control to HAP4 (Forsburg and Guarente, 1989) as occurs with GCN4 (Thireos et al., 1984; Hinnebusch, 1984). HAP4 transcription could be controlled by a system similar to that operating on $S U C 2$ since transcription of $C Y C 1$ is regulated, directly or indirectly by CYC8, TUP1 (Rothstein and Sherman, 1980), HEX2
(Borralho et al., 1989) and CATl (Wright and Poyton, 1990). In addition, the HAP4 promoter contains a sequence (Forsburg and Guarente, 1989) corresponding to the consensus binding site for the negative regulator MIG1 (Griggs and Johnston, 1991); however, the effect of the migl mutation on $C Y C 1$ expression has not yet been tested.

It should be indicated that the influence of glucose on the transcription of the fusion gene is stronger than that on transcription of the $C Y C l$ gene and that the effect of most mutations affecting the fusion gene has not been cross-tested on the expression of $C Y C 1$ itself. It has been reported that hap 2 or hap 3 mutants had cytochrome concentrations up to $50 \%$ of that of a wild-type strain (Mattoon et al., 1990) but it is not clear whether the measurements were made in repressed or derepressed conditions. These results show, in any case, that the complex HAP2/HAP3/HAP4 is not required for basal transcription.

\section{Less well-known systems}

It is not the purpose of this review to list every gene which has been shown to be subject to catabolite repression in yeast. However, a sampling of a number of systems would be useful to show the great diversity of genes controlled by glucose and the different ways in which they appear to be regulated.

\section{NAD-dependent glutamate dehydrogenase}

The NAD-dependent glutamate dehydrogenase from $S$. cerevisiae encoded by the $G D H 2$ gene is an anabolic enzyme used to generate ammonia from glutamate and regulated by the nitrogen source (Holzer and Schneider, 1975; Miller and Magasanik, 1990). The synthesis of this enzyme is also repressed by glucose (Eraso and Gancedo, 1984) and this repression appears to depend on the presence of a repressing nitrogen source like glutamine (Coschigano et al., 1991). The $c y c 8$ mutation allows a partial derepression of $G D H 2$ in the presence of glucose but neither $H X K 2$ nor $H A P 3$ or $H A P 4$ appear to be involved in its regulation; other regulatory mutants which affect other systems subject to catabolite repression have not been tested. Two mutations $\mathrm{rgcl}_{\mathrm{c}}$ and $\mathrm{rgc2}$ have been identified that block derepression of $G D H 2$ in response to the carbon source. It is not yet known whether $R G C 1$ and $R G C 2$ are allelic to previously described regulatory genes but it has been observed that the rgcl mutation does not affect the expression of $C Y C 1$ or $S U C 2$ and that $\mathrm{rgc}$, which causes a petite phenotype, does not interfere with the derepression of $C Y C 1$ in raffinose. Deletion analysis of upstream sequences of $G D H 2$ delineated a region in the promoter involved in catabolite repression (Coschigano et al., 1991). The sequence of the promoter has just been reported (Miller and Magasanik, 1991) and a cursory examination reveals the presence of an element similar to those binding the regulatory protein MIG1.

\section{Protease B}

Protease $B$, a vacuolar serine protease encoded by the PRBI gene, is repressed by glucose (Hansen et al., 1977) at the level of transcription (Moehle et al., 1987). Mutations in the $C A T 1, C A T 3$ or $H X K 2$ genes had no effect on the regulation by glucose, while protease B expression increased in $\operatorname{snf} 2$ and snf5 mutants (Moehle and Jones, 1990). Although the moderate increase in expression (2-3-fold) is only partially coupled with an increase in mRNA level, it has been suggested 
that SNF2 and SNF5 are negative regulators of transcription for $P R B 1$. An alternative interpretation of the results would be that SNF2 and SNF5 are positive regulators of transcription of a regulatory gene (or genes) whose product interferes with the accumulation of protease $B$, either by decreasing $P B R I$ transcription or the stability of the PBR1 mRNA or of the protease $B$ itself.

\section{Mitochondrial proteins}

The regulation of a set of mitochondrial proteins encoded by nuclear genes could proceed in parallel as shown by the fact that glucose decreases in a similar way the rate of transcription of the genes for the $\alpha$ and $\beta$ subunit of the ATPase and for an ATP/ADP translocator (Szekely and Montgomery, 1984). A pet mutant has been identified in which these genes could not be derepressed while the transcription of the CYCl gene was not affected, the mutant however has not been characterized further (Szekely and Montgomery, 1984).

The regulatory circuit controlling another nuclear gene encoding a mitochondrial protein, PET494, also appears to be quite distinctive. The product of PET494 is required for the translation of the cox III mRNA which codes for the subunit III of cytochrome $c$ oxidase (Müller et al., 1984). PET494 expression is controlled by glucose and the degree of repression observed could account for the catabolite repression of cytochrome $c$ oxidase. Using a PET494-lacZ fusion gene it could be shown that PET494 expression does not require the $H A P 2$ product nor the products of $C A T 1$ or $S N F 2$ and that glucose repression is not relieved in a $c y c 8$ or $h x k 2$ mutant (Marykwas and Fox, 1989). It has been suggested that PET494 regulation by carbon source may involve both transcriptional and post-transcriptional controls.

\section{Catalase A}

It has recently been reported that the $C T A I$ gene, which encodes catalase $A$, the peroxisomal catalase of $S$. cerevisiae, and which is repressed by glucose, is regulated by the ADR1 protein. This protein is also required for full derepression of other peroxisomal proteins (Simon et al., 1991). This observation is interesting because it shows that a protein like ADR1 which appeared to play a very specific function in the transcription of $A D H 2$ has in fact pleiotropic effects.

\section{General features}

From the observations on the regulation of different genes discussed above, the following general features may be deduced.

a) Many regulatory trans-acting genes are shared by a variety of systems. Some elements, however, may have a negative effect on a system and a positive one on another. For instance, $c y c 8$ null mutants lack catabolite repression of invertase and in a gal80 background also of $\alpha$-galactosidase but they do not grow on non-fermentable carbon sources (Trumbly, 1988). This suggests that CYC8 can inhibit the transcription of certain genes but is required for the transcription of others.

b) The regulatory circuits controlling different genes are very different and include a great variety of elements.

c) Glucose acts in most cases by modifying the activity of trans-acting elements rather than their transcription rate. This explains why, for many systems, maximal repression of transcription is achieved a few minutes after the addition of glucose
(Zitomer et al., 1979; Szekely and Montgomery, 1984). On the other hand, when total repression of transcription is only attained after 15-20 min, as in the case of maltase (Fedoroff et al., 1983 b), glucose most likely affects the rate of transcription of a regulatory gene.

d) Glucose appears to inhibit activating elements rather than activate inhibitory elements. In no case, however, has the whole sequence of events from glucose uptake to shut-down of transcription been unravelled.

\section{NON-SACCHAROMYCES YEASTS}

Catabolite repression is particularly marked in facultative anaerobes such as $S$. cerevisiae but it is also found in aerobic yeasts like Rhodotorula, Debaryomyces or Pichia (Duntze et al., 1967; Gancedo and Gancedo, 1971). The information about mechanisms of catabolite repression in non-Saccharomyces yeasts is still very scarce but hexokinase appears to be a mediator for the repression by glucose of at least a set of genes in different species like Schwanniomyces occidentalis (McCann et al., 1987) and Pachysolen tannophilus (Wedlock and Thornton, 1989). Mutants with a particular enzyme or pathway insensitive to glucose repression have been also isolated in Hansenula polymorpha (Roggenkamp, 1988) and in Schizosaccharomyces pombe (Hoffman and Winston, 1990). In the first case the mutants with non-repressible synthesis of enzymes involved in methanol oxidation also show a constitutive appearance of peroxisomes but have not been further characterized. For Schizosaccharomyces pombe, the mutants able to express fructose 1,6-bisphosphatase in the presence of glucose have been shown to belong to ten complementation groups that correspond to ten unlinked genes named git. The effect of six of the git mutations is reversed by the addition of cAMP to the growth medium and one of these genes, git2, encodes adenylate cyclase (Hoffman and Winston, 1991). Moreover, a mutant affected in the regulatory subunit of a cAMP-dependent protein kinase, cgs I (McLeod M., cited in Hoffman and Winston, 1991) does not derepress fructose 1,6bisphosphatase. It would appear therefore that catabolite repression of this gene in Schizosaccharomyces pombe is related to the activation of a cAMP-dependent protein kinase (Hoffman and Winston, 1991).

Some elements involved in yeast catabolite repression could be present in other fungi and even in plants. Recently, it has been reported that the product of the creA gene, a negatively acting regulator of catabolite repression in Aspergillus nidulans, has $84 \%$ similarity in its zinc finger region with the MIG1 protein from S. cerevisiae (Dowzer and Kelly, 1991). A gene isolated from rye endosperm and coding for a protein kinase has been shown to perform in yeast the same function as the $C A T l$ product. A comparison of the 80 residues in the central catalytic domain of each protein shows that 69 are identical and 6 represent conservative substitutions (Alderson et al., 1991).

\section{PERSPECTIVES}

I have shown in this review the impressive amount of information on catabolite repression gathered in the last few years. In spite of it, our knowledge on how glucose represses transcription still remains fragmentary. The availability of a system for in vitro transcription will be of great importance to identify the elements which control gene expression in yeast, as happened in the case of E. coli. In the case of yeast, tran- 
Table 8. Bias introduced by the selection procedures in the search for catabolite repression mutants.

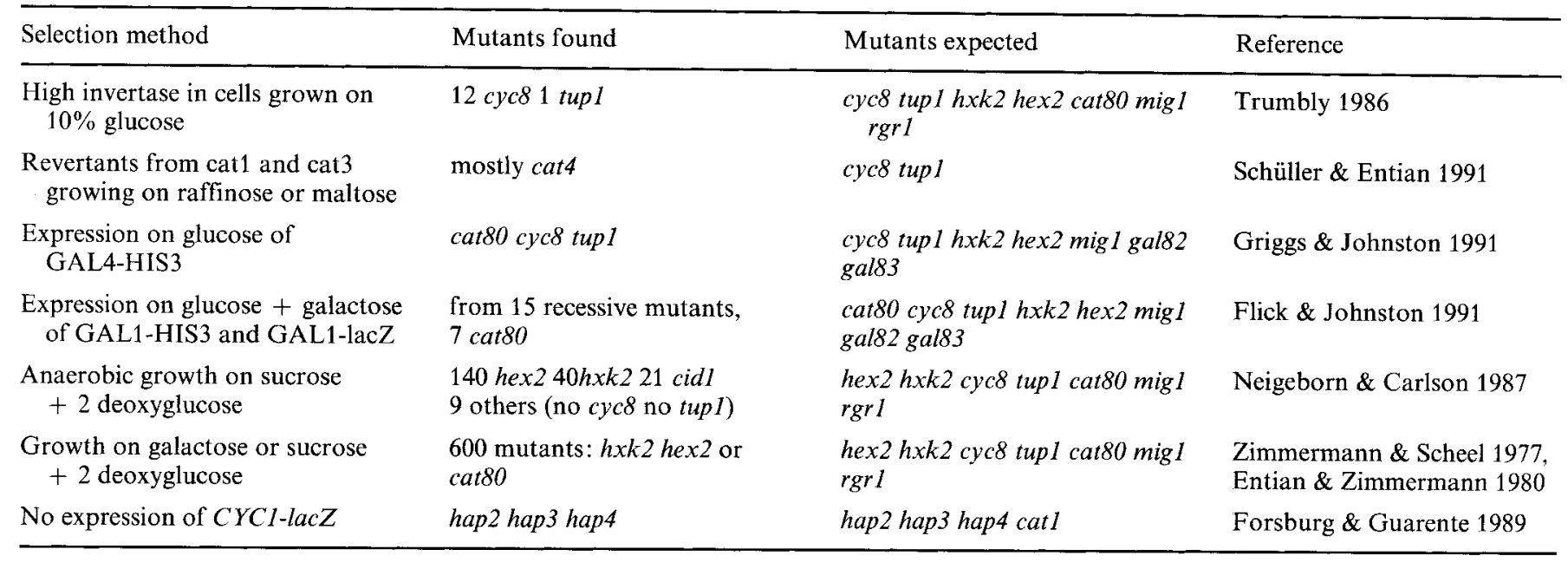

scription in vitro presented for years insoluble problems; however, reliable procedures have been established recently (Lue et al., 1989) and the possibility now exists to perform direct experiments to test the effects of different intermediary elements. However, due to the fact that naked templates are used in vitro and to the complexity of the transcription machinery, it is not yet clear if regulated transcription can be faithfully reconstituted in vitro. Therefore it appears that for some time in the future the isolation and analysis of mutants will still be an important tool in the study of catabolite repression. In this regard it should be considered that the selection of mutants is complicated by the fact that, for reasons not well understood, each selection procedure tends to yield only a limited number of mutant alleles (Trumbly, 1986, Schüller and Entian, 1991). As can be seen in Table 8, selection conditions which should have allowed the isolation of a variety of mutants produced only a limited set. It is thus likely that there are still genes involved in catabolite repression which have not been identified. To detect them, it is necessary to devise selection procedures that should be both powerful and unbiased. The possibility that some of the regulatory proteins yet undiscovered could have pleiotropic effects should be taken into account and therefore the search for conditional mutants should be considered. The use of fusion genes in which the reporter gene allows a growth selection or an easy on-plate test could circumvent some of the difficulties, although the procedure is in some cases hampered by technical problems.

The study of mutants affected in the very early steps of glucose metabolism could be a good starting point in the search for the signal produced by glucose. The possibility that different systems are controlled by different signals should not be overlooked and therefore a diversity of systems should be examined in the search for the mode of action of glucose. Also, to detect whether glucose affects the synthesis of some intermediary elements, it could be useful to investigate the effect of inhibitors of protein synthesis on the onset of repression or derepression.

An important point to keep in mind when studying catabolite repression is the possible relationship between the glucose effect in yeast and the effects of growth factors in mammalian cells. In many aspects glucose can be considered to be a growth factor for a yeast cell and it could be speculated that some elements have been evolutionarily conserved in the different systems. Glucose activation of the yeast plasma membrane proton ATPase and the subsequent acidification of the cytoplasm can be put in parallel with the fact that an early response of eukaryotic cells to stimuli which activate their proliferation is an increase in intracellular $\mathrm{pH}$ (Perona and Serrano, 1988). The HAP2/HAP3/HAP4 system has its counterpart in the CCAAT box-binding factors CP1A and CP1B from HeLa cells (Chodosh et al., 1988) and the MIG1 protein has a $\mathrm{Cys}_{2} \mathrm{His}_{2} \mathrm{Zn}$ finger similar to that of the Wilms tumour protein and to that of proteins encoded by early growth-response genes (Nehlin and Ronne, 1990). It is therefore not too far-fetched to think that some of the regulatory mechanisms used for catabolite repression in yeast have been conserved in higher organisms and utilized for growth control.

I thank all the colleagues, too numerous to be individually listed, who generously supplied me with reprints, preprints or unpublished material pertinent for this review. I thank C. Gancedo for helpful discussions and suggestions on the manuscript. Work in the author's laboratory has been supported by grants from the EEC [BAP 0389 . E JR] and the Spanish Dirección General de Investigación Cientifica y Técnica (PB87-0294).

\section{REFERENCES}

Abrams, E., Neigeborn, L. \& Carlson, M. (1986) Mol. Cell. Biol. 6, $3643-3651$.

Adams, B. G. (1972) J. Bacteriol. 111, 308-315.

Alderson, A., Sabelli, P. A., Dickinson, J. R., Cole, D., Richardson, M., Kreis, M., Shewry, P. R. \& Halford, N. G. (1991) Proc. Natl Acad. Sci. USA 88, 8602-8605.

Bailey, R. B. \& Woodward, A. (1984) Mol. Gen. Genet. 193, 507512.

Bajwa, W., Torchia, T. E. \& Hopper, J. E. (1988) Mol. Cell. Biol. 8 , $3439-3447$.

Beier, D. R. \& Young, E. T. (1982) Nature 300, 724-728.

Beier, D. R., Sledziewski, A. \& Young, E. T. (1985) Mol. Cell. Biol. $5,1743-1749$.

Berger, S. L., Cress, W. D., Cress, A., Triezenberg, S. J. \& Guarente, L. (1990) Cell 61, 1199-1208.

Bhat, P. J., Dahlkyun, O. \& Hopper, J. E. (1990) Genetics 125, $281-$ 291.

Bisson, L. F. (1988) J. Bacteriol. 170, 4838-4845.

Bisson, L. F. \& Fraenkel, D. G. (1983) Proc. Natl Acad. Sci. USA 80, $1730-1734$.

Blumberg, H., Hartshorne, T. A. \& Young, E. T. (1988) Mol. Cell. Biol. 8, 1868-1876. 
Böker-Schmitt, E., Francisci, S. \& Schweyen, R. J. (1982) J. Bacteriol. $151,303-310$.

Borratho, L. M., Malamud, D. R., Panek, A. D., Tenan, M. N., Oliveira, D. E. \& Mattoon, J. R. (1989) J. Gen. Microbiol. 135, $1217-1227$.

Breunig, K. D. (1989) Mol. Gen. Genet. 216, 422-427.

Calder, K. M. \& McEwen, J. E. (1990) Nucleic Acids Res. 18, 1632.

Carlson, M., Osmond, B. C., Neigeborn, L. \& Botstein, D. (1984) Genetics 107, 19-32.

Celenza, J. L. \& Carlson, M. (1984) Mol. Cell. Biol. 4, 54-60.

Celenza, J. L. \& Carlson, M. (1986) Science 233, 1175-1180.

Celenza, J. L. \& Carlson, M. (1989) Mol. Cell. Biol. 9, 5034-5044.

Celenza, J. L., Marshall-Carlson L. \& Carlson, M. (1988) Proc. Natl Acad. Sci. USA 85, 2130-2134.

Celenza, J. L., Eng, F. J. \& Carlson, M. (1989) Mol. Cell. Biol. 9, $5045-5054$.

Cherry, J. L., Johnson, T. R., Dollard, C., Shuster, J. R. \& Denis, C. (1989) Cell 56, 409-419.

Chiang, H. L. \& Schekman, R. (1991) Nature 350, 313-318.

Chodosh, L. A., Olesen, J. T., Hahn, S., Baldwin, A. S., Guarente, L. \& Sharp, P. A. (1988) Cell 53, 25-35.

Ciriacy, M. (1975) Mol. Gen. Genet. 138, 157-164.

Ciriacy, M. (1977) Mol. Gen. Genet. 154, 213-220.

Ciriacy, M. (1978) Mol. Gen. Genet. 159, 329-335.

Ciriacy, M. (1979) Mol. Gen. Genet. 176, 427-431.

Coschigano, P. W., Miller, S. M. \& Magasanik, B. (1991) Mol. Cell. Biol. 11, 4455-4465.

Denis, C. L. (1984) Genetics 108, 833-844.

Denis, C. L. (1987) Mol. Gen. Genet. 208, 101-106.

Denis, C. L. \& Gallo, C. (1986) Mol. Cell. Biol. 6, 4026-4030.

Denis, C. L. \& Malvar, T. (1990) Genetics 124, 283-291.

Denis, C. L. \& Young, E. T. (1983) Mol. Cell. Biol. 3, 360-370.

Denis, C. L., Ciriacy, M. \& Young, E. T. (1981) J. Mol. Biol. 148, $355-368$.

Douglas, H. C. \& Hawthorne, D. C. (1966) Genetics 54, 911 - 916.

Dowzer, C. E. A. \& Kelly, J. M. (1991) Mol. Cell. Biol. 11, $5701-$ 5709.

Duntze, W., Atzpodien, W. \& Holzer, H. (1967) Arch. Mikrobiol. 58 , $296-301$.

Entian, K. D. (1980) Mol. Gen. Genet. 178, 633-637.

Entian, K. D. (1986) Microbiol. Sci. 3, 366-371.

Entian, K. D. \& Fröhlich, K. U. (1984) J. Bacteriol. 158, 29-35.

Entian, K. D. \& Loureiro-Dias, M. C. (1990) J. Gen. Microbiol. 136, $855-860$.

Entian, K. D. \& Zimmermann, F. K. (1980) Mol. Gen. Genet. 177, $345-350$

Entian, K. D. \& Zimmermann, F. K. (1982) J. Bacteriol. 151, $1123-$ 1128

Entian, K. D., Hilberg, F., Opitz, H. \& Mecke, D. (1985) Mol. Cell. Biol. 5, 3035-3040.

Eraso, P. \& Gancedo, J. M. (1984) Eur. J. Biochem. 141, 195-198.

Estruch, F. \& Carlson, M. (1990a) Nucleic Acids Res. 18, 6959-6964.

Estruch, F. \& Carlson, M. (1990b) Mol. Cell. Biol. 10, 2544-2553.

Federoff, H. J., Eccleshall, T. R. \& Marmur, J. (1983a) J. Bacteriol. $154,1301-1308$.

Federoff, H. J., Eccleshall, T. R. \& Marmur, J. (1983b) J. Bacteriol. $156,301-307$.

Fernández, R., Herrero, P., Fernández, E., Fernández, T., LópezBoado, Y. S. \& Moreno, F. (1988) J. Gen. Microbiol. 134, 2493 2498.

Fields, S. \& Song, O. K. (1989) Nature 340, $245-246$.

Finley, R. L. Jr, Chen, S., Ma, J., Byrne, P. \& West, R. W. Jr (1990) Mol. Cell. Biol. 10, 5663-5670.

Flanagan, P. M., Kelleher, R. J. III, Sayre, M. H., Tschochner, H. \& Kornberg, R. D. (1991) Nature 350, 436-438

Flick, J. S. \& Johnston, M. (1990) Mol. Cell. Biol. 10, 4757-4769.

Flick, J. S. \& Johnston, M. (1991) Mol. Cell. Biol. 11, $5101-5112$.

Forsburg, S. L. \& Guarente, L. (1988) Mol. Cell. Biol. 8, 647-654.

Forsburg, S. L. \& Guarente, L. (1989) Genes \& Dev. 3, 1166-1178.

Fujita, A., Matsumoto, S., Kuhara, S., Misumi, Y. \& Kobayashi, H. (1990) Gene 89, $93-99$.

Gancedo, J. M. \& Gancedo, C. (1971) Arch. Mikrobiol. 76, 132-138.
Gancedo, C. \& Gancedo, J. M. (1985) Eur. J. Biochem. 148, $593-$ 597.

Gancedo, J. M. \& Gancedo, C. (1986) FEBS Microbiol. Rev. 32, $179-$ 187.

Gancedo, C. \& Schwerzmann, K. (1976) Arch. Microbiol. 109, 221 225.

Gancedo, C. \& Serrano, R. (1989) in The yeasts (Rose, A. H. \& Harrison, J. S., eds) vol. 3, 2nd ed., pp. 205-259, Academic Press, London.

Gancedo, J. M., Clifton, D. \& Fraenkel D. G. (1977) J. Biol. Chem $252,4443-4444$

Giniger, E., Varnum, S. \& Ptashne, M. (1985) Cell 40, 767-774.

Griggs, D. W. \& Johnston, M. (1991) Proc. Natl Acad. Sci. USA 88, $8597-8601$

Guarente, L. \& Ptashne, M. (1981) Proc. Natl Acad. Sci. USA 78, $2199-2203$

Guarente, L., Lalonde, B., Gifford, P. \& Alani, E. (1984) Cell 36, $503-511$.

Hahn, S. \& Guarente, L. (1988) Science 240, 317-321

Hahn, S., Pinkham, J., Wei, R., Miller, R. \& Guarente, L. (1988) Mol Cell. Biol. 8, 655-663.

Hansen, R. J., Switzer, R. L., Hinze, H. \& Holzer, H. (1977) Biochim. Biophys. Acta 496, 103-114.

Hashimoto, H., Kikuchi, Y., Nogi, Y. \& Fukasawa, T. (1983) Mol. Gen. Genet. 191, 31-38.

Herrero, P., Fernández, R. \& Moreno, F. (1989) J. Gen. Microbiol. $135,1209-1216$.

Hinnebusch, A. G. (1984) Proc. Natl Acad. Sci. USA 81, 6442-6446.

Hirano, T., Kinoshita, N., Marikawa, K. \& Yanagida, M. (1990) Cell $60,319-328$.

Hoffman, C. S. \& Winston, F. (1990) Genetics 124, 807-816.

Hoffman, C. S. \& Winston, F. (1991) Genes \& Dev. 5, 561-571.

Hohmann, S. \& Gozalbo, D. (1988) Mol. Gen. Genet. 211, 446-454.

Holzer, H. \& Schneider, S. (1975) Biochem. Z. 329, 361 - 369.

Hong, S. H. \& Marmur, J. (1986) Gene 4I, 75-84.

Hong, S. H. \& Marmur, J. (1987) Mol. Cell. Biol. 7, 2477-2483.

Hooft van Huijsduijnen, R., Li, X. Y., Black, D., Matthes, H. Benoist, C. \& Mathis, D. (1990) EMBO J. 9, 3119-3127.

Hopper, J. E., Broach, J. R. \& Rowe, L. B. (1978) Proc. Natl Acad. Sci. USA 75, 2878-2882.

Johnston, M. (1987) Microbiol. Rev. 51, 458-476.

Johnston, S. A. \& Hopper, J. E. (1982) Proc. Natl Acad. Sci. USA 79 , $6971-6975$.

Laughon, A. \& Gesteland, R. F. (1982) Proc. Natl Acad. Sci. USA $79,6827-6831$.

Laurent, B. C., Treitel, M. A. \& Carlson, M. (1990) Mol. Cell. Biol. $10,5616-5625$.

Laurent, B. C., Treitel, M. A. \& Carlson, M. (1991) Proc. Natl Acad. Sci. USA 88, 2687-2691.

Lemmont, J. F. (1977) Mutat. Res. 43, 179-203

Lobo, Z. \& Maitra, P. K. (1977) Genetics 86, 727-744.

Lue, N. F., Buchman, A. R. \& Kornberg R. D. (1989) Proc. Natl Acad. Sci. USA 86, 486-490.

Ma, H. \& Botstein, D. (1986) Mol. Cell. Biol. 6, 4046-4052.

Ma, H., Bloom, L. M., Zhu, Z., Walsh, C. T. \& Botstein, D. (1989a) Mol. Cell. Biol. 9, 5630-5642.

Ma, H., Bloom, L. M., Walsh, C. T. \& Botstein, D. (1989b) Mol. Cell. Biol. 9, 5643-5649.

Maarse, A. C., de Haan, M., Bout, A. \& Grivell, L. A. (1988) Nucleic Acids Res. 16, 5797-5811.

MacKay, V. L. (1983) Methods Enzymol. 101, 325-343.

Marshall-Carlson, L., Celenza, J. L., Laurent, B. C. \& Carlson, M. (1990) Mol. Cell. Biol. 10, 1105-1115.

Martegani, E., Porro, D., Lotti, M. \& Alberghina, L. (1990) Yeast 6 , S290.

Marykwas, D. L. \& Fox, T. D. (1989) Mol. Cell. Biol. 9, 484-491

Matsumoto, K., Toh-e, A. \& Oshima, Y. (1981) Mol. Cell. Biol. I, $83-93$.

Matsumoto, K, Uno, I., Toh-E, A., Ishikawa, T. \& Oshima, Y. (1982) J. Bacteriol. 150, 277-285.

Matsumoto, K, Uno, I., Ishikawa, T. \& Oshima, Y. (1983a) $J$. Bacteriol. 156, 898-900. 
Matsumoto, K., Yoshimatsu, T. \& Oshima, Y. (1983b) J. Bacteriol. I53, 1405-1414.

Matsumoto, K., Uno, I. \& Ishikawa, T. (1984) Genetics 108, 53-66.

Mattoon, J. R., Carvajal, E. \& Guthrie D. (1990) Curr. Genet. 17, $179-183$.

McCann, A. K., Hilberg, F., Kenworthy, P. \& Barnett, J. A. (1987) J. Gen. Microbiol. 133, $381-389$.

Mercado, J. J., Vincent, O. \& Gancedo J. M. (1991) FEBS Lett. 291, $97-100$.

Meyer, J., Walker-Jonah, A. \& Hollenberg, C. P. (1991) Mol. Cell. Biol. 11, 5454-5461.

Michels, C. A. \& Romanowski, A. (1980) J. Bacteriol. 143, 674679.

Miller, S. M. \& Magasanik, B. (1990) J. Bacteriol. 172, 4927-4935.

Miller, S. M. \& Magasanik, B. (1991) Mol. Cell. Biol. 11, 6229-6247.

Mitchell, P. M. \& Tjian, R. (1989) Science 245, 371-378.

Moehle, C. M. \& Jones, E. W. (1990) Genetics 124, 39-55.

Moehle, C. M., Aynardi, M. W., Kolodny, M. R., Park, F. J. \& Jones, E. W. (1987) Genetics 115, 255-263.

Müller, P. P., Reif, M. K., Zonghou, S., Sengstag, C., Mason, T. L. \& Fox, T. D. (1984) J. Mol. Biol. 175, 431-452.

Mylin, L. M., Bhat, J. P. \& Hopper, J. E. (1989) Genes \& Dev. 3, $1157-1165$.

Nehlin, J. O. \& Ronne, H. (1990) EMBO J. 9, $2891-2898$.

Nehlin, J. O., Carlberg, M. \& Ronne, H. (1991) EMBO J. 10, $3373-$ 3378.

Neigeborn, L. \& Carlson, M. (1984) Genetics 108, 845-858.

Neigeborn, L. \& Carlson, M. (1987) Genetics 115, 247-253.

Neigeborn, L., Rubin, K. \& Carlson, M. (1986) Genetics 112, 741 753.

Neigeborn, L., Celenza, J. L. \& Carlson, M. (1987) Mol. Cell. Biol. $7,672-678$.

Niederacher, D. \& Entian, K. D. (1987) Mol. Gen. Genet. 206, 505509

Niederacher, D. \& Entian, K. D. (1991) Eur. J. Biochem. 200, $311-$ 319.

Nogi, Y., Shimada, H., Matsuzaki, Y., Hashimoto, H. \& Fukasawa, T. (1984) Mol. Gen. Genet. 195, 29-34.

O'Hara, P. J., Horowitz, H., Eichinger, G. \& Young, E. T. (1988) Nucleic Acids Res. 16, 10153-10169.

Olesen, J. T. \& Guarente, L. (1990) Genes \& Dev. 4, 1714-1729.

Olesen, J. T., Hahn, S. \& Guarente, L. (1987) Cell 51, 953-961.

Oshima, Y. (1982) in The molecular biology of the yeast Saccharomyces, metabolism and gene expression (Strathern, J., Jones, E. \& Broach J. R., eds.) vol. 1, pp. 159-180, Cold Spring Harbor Laboratory, Cold Spring Harbor NY.

Perona, R. \& Serrano, R. (1988) Nature 334, 438-440.

Pinkham, J. L. \& Guarente, L. (1985) Mol. Cell. Biol.5, 3410-3416.

Pinkham, J. L., Olesen, J. T. \& Guarente, L. (1987) Mol. Cell. Biol. 7, 578-586.

Polakis, E. S. \& Bartley, W. (1965) Biochem. J. 97, 284-297.

Riley, M. I. \& Dickson, R. C. (1984) J. Bacteriol. 158, 705-712.

Roggenkamp, R. (1988) Mol. Gen. Genet. 213, 535-540.

Rose, M., Albig, W. \& Entian, K. D. (1991) Eur. J. Biochem. 199, $511-518$.

Rothstein, R. J. \& Sherman, F. (1980) Genetics 94, 871-889.

Saier, M. H. Jr (1989) Microbiol. Rev. 53, 109-120.

Sakai, A., Shimizu, Y. \& Hishinuma, F. (1988) Genetics 119, $499-$ 506.

Sakai, A., Shimizu, Y., Kondou, S., Chibazakura, T. \& Hishinuma, F. (1990) Mol. Cell. Biol. 10, 4130-4138.

Sarokin, L. \& Carlson, M. (1984) Mol. Cell. Biol. 4, 2750-2757.

Sarokin, L. \& Carlson, M. (1985a) Mol. Cell. Biol. 5, 2521-2526.

Sarokin, L. \& Carlson, M. (1985b) Nucleic Acids Res. 13, $6089-$ 6103 .

Sarokin, L. \& Carlson, M. (1986) Mol. Cell. Biol. 6, 2324-2333.

Schamhart, D. H. J., Ten Berge, A. M. A. \& Van de Poll, K. W. (1975) J. Bacteriol. 121, 747-752.

Schüller, H. J. \& Entian, K. D. (1987) Mol. Gen. Genet. 209, $366-$ 373.
Schüller, H. J. \& Entian, K. D. (1988) Gene 67, 247-257.

Schüller, H. J. \& Entian, K. D. (1991) J. Bacteriol. 173, 2045-2052.

Schultz, J. \& Carlson, M. (1987) Mol. Cell. Biol. 7, 3637-3645.

Schultz, J., Marshall, L. \& Carlson, M. (1990) Mol. Cell. Biol. 10 4744-4756

Selleck, S. B. \& Majors, J. E. (1987) Mol. Cell. Biol. 7, 3260-3267.

Shuster, J. R., Yu, J., Cox, D., Chan, R. V. L., Smith, M. \& Young, E. T. (1986) Mol. Cell. Biol. 6, 1894-1902.

Sikorski, R. S., Boguski, M. S., Goebl, M. \& Hieter, P. (1990) Cell $60,307-317$

Simon, M., Adam, G., Rapatz, W., Spevak, W. \& Ruis, H. (1991) Mol. Cell. Biol. 11, 699-704.

Stark, H. C., Fugit, D. \& Mowshowitz, D. B. (1980) Genetics 94, $921-928$

Struhl, K. (1985) Nature 317, 822-824.

Swanson, M. S., Carlson, M. \& Winston, F. (1990) Mol. Cell. Biol. $10,4935-4941$

Szekely, E. \& Montgomery, D. L. (1984) Mol. Cell. Biol. 4, 939-946.

Taguchi, A. K. W. \& Young, E. T. (1987) Genetics 116, 523-530.

Taylor, W. E. \& Young, E. T. (1990) Proc. Natl Acad. Sci. USA 87, 4098-4102.

Thireos, G., Penn, M. D. \& Greer, H. (1984) Proc. Natl Acad. Sci. USA 81, 5096-5100.

Torchia, T. E. \& Hopper, J. E. (1986) Genetics 113, 229-246.

Torchia, T. E., Hamilton, R. W., Cano, C. L. \& Hopper, J. E. (1984) Mol. Cell. Biol. 4, 1521-1527.

Trash-Bingmam, C. \& Fangman, W. L. (1989) Mol. Cell. Biol. 9 $809-816$

Trumbly, R. J. (1986) J. Bacteriol. 166, 1123-1127.

Trumbly, R. J. (1988) Gene 73, 97-111.

Ullmann, A. (1985) Biochimie 67, 29-34.

Van Aelst, L., Jans, A. W. \& Thevelein J. M. (1991) J. Gen. Microbiol. $137,341-349$.

Vojtek, A. B. \& Fraenkel, D. G. (1990) Eur. J. Biochem. 190, $371-$ 375 .

Wedlock, D. N. \& Thornton, R. J. (1989) J. Gen. Microbiol. 135, 2013-2018

West, R. W. Jr, Yocum, R. R. \& Ptashne, M. (1984) Mol. Cell. Biol. 4, 2467-2478.

West, R. W. Jr, Chen, S., Putz, H., Butler, G. \& Banerjee, M. (1987) Genes \& Dev. 1, 1118-1131.

Wickner, R. B. (1974) J. Bacteriol. 117, 252-260.

Williams, F. E. \& Trumbly, R. J. (1990) Mol. Cell. Biol. 10, 65006511.

Williams, F. E., Varanasi, U. \& Trumbly, R. J. (1991) Mol. Cell. Biol. $11,3307-3316$.

Williamson, V. M., Young, E. T. \& Ciriacy, M. (1981) Cell 23, $605-$ 614

Witt, I., Kronau, R. \& Holzer, H. (1966) Biochim. Biophys. Acta 118, $522-537$

Wray, L. V. Jr, Witte, M. M., Dickson, R. C. \& Riley, M. I. (1987) Mol. Cell. Biol. 7, 1111-1121.

Wright, R. M. \& Poyton, R. O. (1990) Mol. Cell. Biol. 10, $1297-$ 1300.

Yocum, R. R. \& Johnston, M. (1984) Gene 32, 75-82.

Yoshimoto, H. \& Yamashita, I. (1991) Mol. Gen. Genet. 228, 270280.

Yu, J., Donoviel, M. S. \& Young, E. T. (1989) Mol. Cell. Biol. 9, 3442.

Zimmermann, F. K. \& Scheel, I. (1977) Mol. Gen. Genet. 154, 7582.

Zimmermann, F. K., Kaufmann, I., Rasemberg, H. \& Hausmann, P. (1977) Mol. Gen. Genet. 151, 95-103.

Zitomer, R. S. \& Nichols, D. L. (1978) J. Bacteriol. 135, 39 - 44.

Zitomer, R. S., Montgomery, D. L., Nichols, D. L. \& Hall, B. D. (1979) Proc. Natl Acad. Sci. USA 76, 3627-3631. 